\title{
The representation and processing of identical cognates by late bilinguals: RT and ERP effects
}

\author{
David Peeters $^{\mathrm{a}, *}$, Ton Dijkstra ${ }^{\mathrm{b}}$, Jonathan Grainger $^{\mathrm{c}}$ \\ ${ }^{a}$ Radboud University, Donders Institute for Brain, Cognition and Behaviour, Max Planck Institute for Psycholinguistics, \\ International Max Planck Research School for Language Sciences, Nijmegen, The Netherlands \\ ${ }^{\mathrm{b}}$ Radboud University, Donders Institute for Brain, Cognition and Behaviour, Nijmegen, The Netherlands \\ ${ }^{\mathrm{c}}$ Aix-Marseille University, CNRS, Marseille, France
}

\section{A R T I C L E I N F O}

\section{Article history:}

Received 11 October 2011

revision received 19 December 2012

\section{Keywords:}

Bilingual word recognition

Cognate representation

Word frequency

N400 effect

\begin{abstract}
A B S T R A C T
Across the languages of a bilingual, translation equivalents can have the same orthographic form and shared meaning (e.g., TABLE in French and English). How such words, called orthographically identical cognates, are processed and represented in the bilingual brain is not well understood. In the present study, late French-English bilinguals processed such identical cognates and control words in an English lexical decision task. Both behavioral and electrophysiological data were collected. Reaction times to identical cognates were shorter than for non-cognate controls and depended on both English and French frequency. Cognates with a low English frequency showed a larger cognate advantage than those with a high English frequency. In addition, N400 amplitude was found to be sensitive to cognate status and both the English and French frequency of the cognate words. Theoretical consequences for the processing and representation of identical cognates are discussed.
\end{abstract}

(c) 2013 Elsevier Inc. All rights reserved.

\section{Introduction}

Reading words involves the mapping of orthographic forms onto meaning representations. Because this mapping is often opaque and arbitrary, it may be hard to read words in a less familiar second language (L2). For instance, there is no obvious clue for a native speaker of French that the English word TREE corresponds to the French word ARBRE. This mapping problem is greatly reduced for words that have a similar form and meaning across languages, so-called cognates. For instance, a French person reading an English book will easily understand the words FILM, TAXI, and RESTAURANT, because they exist in both French and English. At present, researchers have not yet studied how such words, called orthographically identical (in short: identical) cognates, are processed and represented in the bilingual brain. The present study investigates this issue by contrasting and testing three theoretical views

\footnotetext{
* Corresponding author. Address: DCCN, P.O. Box 9101, 6500 HB Nijmegen, The Netherlands. Fax: +31 (0)24 3610989.

E-mail address: david.peeters@mpi.nl (D. Peeters).
}

on the representation of such identical cognates. To set the stage for a discussion of these views, we will first provide some background information on the recognition of cognate words by bilinguals.

Cognates have been used in a large number of studies that investigated whether access to the bilingual lexicon is language-selective or not, i.e., whether or not only words in the target language or in the context-relevant language are considered for recognition during reading. Under the hypothesis of language-selective lexical access (e.g., Scarborough, Gerard, \& Cortese, 1984; Soares \& Grosjean, 1984), the processing of cognates should not differ from that of matched control words. In contrast, evidence against the language-selective hypothesis would be provided by any processing differences seen between cognates and their matched non-cognate control words. Such differences would arise if the context-irrelevant reading of the cognate has been activated as well (a situation called 'language non-selective access', see Dijkstra \& Van Heuven, 2002). For instance, if a Dutch-English bilingual is faster to process the L2 English word MELON than a matched 
L2 control word, this implies that the L1 Dutch translation equivalent MELOEN has been activated as well.

The large majority of available studies have observed a faster and more accurate processing of cognates relative to matched control words. This so-called cognate facilitation effect has arisen in behavioral studies on isolated words (Caramazza \& Brones, 1979; Cristoffanini, Kirsner, \& Milech, 1986; Davis et al., 2010; De Groot \& Nas, 1991; Dijkstra, Grainger, \& Van Heuven, 1999; Dijkstra, Miwa, Brummelhuis, Sappelli, \& Baayen, 2010; Dijkstra, Van Jaarsveld, \& Ten Brinke, 1998; Font, 2001; Lemhöfer \& Dijkstra, 2004; Lemhöfer, Dijkstra, \& Michel, 2004; SánchezCasas, Davis, \& García-Albea, 1992; Van Hell \& Dijkstra, 2002; Voga \& Grainger, 2007) and more recently also for cognates in sentence context (Duyck, Van Assche, Drieghe, \& Hartsuiker, 2007; Libben \& Titone, 2009; Schwartz \& Kroll, 2006; Van Assche, Drieghe, Duyck, Welvaert, \& Hartsuiker, 2010; Van Assche, Duyck, Hartsuiker, \& Diependaele, 2009; Van Hell \& De Groot, 2008).

The cognate facilitation effect has not only been reported in behavioral studies, but also in ERP studies. Midgley, Holcomb, and Grainger (2011) recorded the electroencephalogram (EEG) of late, unbalanced EnglishFrench bilinguals while they processed cognates and matched control words in an English (L1) and a French (L2) language block. Participants performed a semantic categorization task on animal names. By asking for overt responses only when items were animal names, no behavioral responses needed to be given to the critical items (words from non-animal categories). In both language blocks, ERPs were found to be sensitive to cognate status. The N400 component, which is argued to reflect how difficult it is to process a word and grasp its meaning (Lau, Phillips, \& Poeppel, 2008; Midgley et al., 2011), was more negative in both language blocks for control words compared to cognates. This led the authors to conclude that the mapping from form to meaning is facilitated for cognates, and, in line with current consensus in the literature, that access to the bilingual lexicon is language nonselective.

If cognate facilitation occurs because cognates share their form across languages, then a greater form overlap should lead to larger facilitation. Dijkstra et al. (2010) let Dutch-English bilinguals perform an L2 English lexical decision task in which both identical cognates (e.g., FRUIT with an identical form and meaning in Dutch and English) and near-identical cognates (e.g., MELON, translated as MELOEN in Dutch) were presented. They showed that, indeed, the cognate facilitation effect becomes larger with an increase in orthographic similarity between the two readings of the cognate. In the case of identical cognates, an increase in phonological overlap also led to a decrease in reaction times in a lexical decision task. Dijkstra et al. (2010) explained the cognate facilitation effect by the coactivation of lexical candidates. When Dutch-English bilinguals read a non-identical cognate, the Dutch and the English orthographic word forms are both activated, apparently as a function of their cross-lingual orthographic overlap. Both activated word forms then activate the shared meaning of the cognate. This results in facilitated processing compared to control words, the meaning of which is activated by only one orthographic and one phonological representation.

Interestingly, in this study identical cognates showed a discontinuously large facilitation effect compared to nearidentical cognates. This discontinuity calls into question whether identical cognates are represented in the same way in the bilingual lexicon as near-identical cognates. It seems intuitively clear that non-identical cognates must be characterized by two different representations (one for each language), but it is as yet unclear at what level identical cognates are represented twice in the bilingual brain.

\section{The representation(s) of identical cognates}

We will now describe three theoretical positions with respect to the representation of identical cognates to be tested in our combined RT/ERP study.

According to a first theoretical position (henceforth the shared-morpheme view), as proposed by Kirsner and colleagues (Cristoffanini et al., 1986; Kirsner, Lalor, \& Hird, 1993; Lalor \& Kirsner, 2000) and by Sánchez-Casas and colleagues (Davis et al., 2010; Sánchez-Casas \& García-Albea, 2005; Sánchez-Casas et al., 1992), cognates, just like morphologically related words in a single language, share a single morphemic representation between languages. Recently, Davis et al. (2010) outlined this proposal, stating that the bilingual lexicon may be structured on the basis of morphological properties, such that words from different languages that have the same etymological root share a representation at the morphological level. In other words, such morphological representations would be independent of language. The shared morphemic representation for cognates, located between a form and a lemma level, then underlies the cognate advantage in processing due to the cognates' shared root. This first position accounts for the identical cognate facilitation effect in terms of a cumulative frequency effect (Davis et al., 2010). Because identical cognates exist in two languages, they are on average encountered much more frequently by the bilinguals than matched control words; their summed frequency of usage strengthens their shared morphological representation relative to controls, resulting in faster and more accurate recognition.

A second theoretical position (Midgley et al., 2011; Voga \& Grainger, 2007) is that identical cognates have a shared orthographic representation, two phonological representations, and a shared semantic representation. This view explains cognate facilitation in terms of orthographic-semantic resonance. The one orthographic and two phonological cognate representations activate a shared semantic representation, which leads to a stronger semantic activation relative to monolingual control words having only one orthographic and one phonological representation. The semantic level sends feedback to the orthographic representation, thus increasing the activation of both cognate readings. We will henceforth call this the form-overlap view. Because identical cognates have exactly the same orthographic form in the two languages of a bilingual, they are assumed to require only one shared orthographic representation. In addition, cognates are assumed to have two phonological representations, such as the word TABLE that is pronounced differently in French 
than in English. Finally, identical cognates have a shared meaning. Like the first theoretical view, according to this second view cognate facilitation is sensitive to cumulative frequency (Midgley et al., 2011). For instance, when French-English bilinguals are visually presented with the identical cognate TABLE they will process this cognate faster than a matched control word that is exclusively French or English, because the word TABLE has been encountered and used not in one but in two languages (Gollan \& Silverberg, 2001). However, whereas the first view attributes the cumulative frequency advantage to the level of the (shared) morphological representation, the second view puts it at the level of the shared orthographic representation.

A third theoretical position (see Dijkstra \& Van Heuven, 2002; Dijkstra et al., 1998, 1999; Van Hell \& Dijkstra, 2002) is that identical cognates are characterized by one orthographic representation, two phonological representations, and a shared semantic representation. In addition, this account assumes that an identical cognate has two languagespecific morphemes. As in the form overlap view, the mechanism underlying cognate facilitation is resonance between the orthographic representation and the other representations (see Fig. 1 in Dijkstra et al. (2010)). Prima facie it might not seem optimally efficient to have, at some level, two representations for the same word. However, when we keep in mind that identical cognates may have different plural markers, gender, and/or relative frequencies across languages and are generally learnt in a different context (e.g., L1 at home, L2 at school or abroad), this proposal becomes more reasonable. Note that language-specific plural markers, gender, and relative frequencies can be linked to such a language-specific morpheme for both readings of the identical cognates. We will refer to this position as the two-morpheme view.

The two-morpheme view has in common with the form-overlap view that it assumes that identical cognates have two phonological representations. Further, like the shared-morpheme view, it underlines that cognates are represented at the morphological level. However, the two-morpheme view states that cognates have two language-specific morphological representations. Whereas the form-overlap view and the shared-morpheme view argue that cognate facilitation must be sensitive to cumulative frequency, the two-morpheme view does not. The latter view underlines that, when a cognate is read, its single orthographic representation and both its phonological and morphological representations are activated, but depending on the context (e.g., the experimental task, stimulus list composition, or target language), one of both representations will be more important.

In the present study, specified next, we aim at empirically contrasting these three views in a combined RT and ERP experiment. Because the shared-morpheme view and the form-overlap view both consider cognate processing to be sensitive to cumulative frequency, we will contrast those two views with the two-morpheme view.

\section{The present study}

We will test how identical cognates are processed by late French-English bilinguals by comparing RTs and ERPs to identical cognates and control words. Four groups of cognates will be distinguished by orthogonally manipulating the relative word frequency (high vs. low) of the French and English readings of a cognate. Cognates will be high frequency in English and French (HEHF), high frequency in English and low frequency in French (HELF), low frequency in English and high frequency in French (LEHF), or low frequency in both languages (LELF). Comparable designs have successfully been used to study interlingual homographs from a behavioral perspective (Dijkstra et al., 1998) and in an electrophysiological investigation (Kerkhofs, Dijkstra, Chwilla, \& De Bruin, 2006), as well as to study syllable frequency effects in L2 bilingual speech production (Alario, Goslin, Michel, \& Laganaro, 2010).

The present study is the first to manipulate the word frequency of both readings of a cognate. Because identical cognates have the same orthographic form and meaning across languages, their frequency of occurrence in different languages is usually highly correlated (see Schepens, Dijkstra, \& Grootjen, 2012). This complicates a frequency manipulation for certain language combinations, e.g., Dutch and English. Nevertheless, for other language pairs, it is possible to differentiate the frequencies of a cognate in the two languages. For instance, the English-French cognate ASSASSIN is relatively high frequency in French, but relatively low frequency in English, possibly because in English its synonym MURDERER is used more often.

We not only collected RTs but also ERPs during the processing of target words by French-English bilinguals. Whereas the RT in lexical decision reflects the combined time it takes to recognize a word and make a decision on it, an ERP provides a more continuous reflection of the processes that underlie word reading (Holcomb \& Grainger, 2006). In particular the N400 is expected to be informative in the present study. This negative-going component that peaks around $400 \mathrm{~ms}$ after the onset of a word, is known to be sensitive to word frequency (Kerkhofs et al., 2006; Münte et al., 2001; Van Petten \& Kutas, 1990), cognate status (Midgley et al., 2011), and both variables combined (Strijkers, Costa, \& Thierry, 2010).

In the present study, we will first aim to replicate the cognate facilitation effect as reflected in faster RTs for cognates compared to control words, and in a more negative going N400 for control words compared to cognates. In addition, we expect to find an overall RT and N400 effect of English frequency, in that high frequency English stimuli will yield faster RTs and a less negative N400 amplitude than low frequency English stimuli. Subsequently, we will analyze the RTs and ERPs from the four cognate conditions separately. This will allow us to contrast the cumulative frequency accounts (the form-overlap and the shared-morpheme view) with the two-morpheme view.

With respect to the RT and ERP data, the form-overlap view and the shared-morpheme view outlined above predict that the cumulative frequency of the two readings of a cognate will determine its processing speed and the N400 amplitude it will yield. In the case of unbalanced bilinguals, the subjective frequency of exposure to the L1 reading of the cognate will generally be higher than to the $\mathrm{L} 2$ reading. For instance, late unbalanced FrenchEnglish bilinguals will have encountered the identical 
cognate TABLE more often in a French than in an English context. Consequently, the cognate items with a high frequency in the L1 of the participants (French) should benefit from the higher cumulative exposure compared to the items with a low frequency in the L1 of the participant. Because unbalanced bilinguals encounter identical cognates less often in their L2 than in their L1, the frequency of the $\mathrm{L} 2$ reading will have a secondary effect. In sum, these accounts predict an increase in RTs and an increase in negative N400 amplitude over test conditions in the order HEHF-LEHF-HELF-LELF. Thus, in general, these two accounts would predict a primary effect of L1 French frequency, and a secondary effect of L2 English frequency of our cognate stimuli.

In contrast, the two-morpheme view predicts that, when a French-English bilingual reads an identical cognate in English, the French and the English morphological representations are both activated and they both activate their shared semantics. In English lexical decision, RTs and N400 amplitude will depend most on the task-relevant L2 English reading of the cognate, whereas the L1 French reading will have a secondary effect, because it will also become activated due to the identical form. Therefore, this account predicts an increase in RTs and an increase in N400 amplitude for conditions in the order HEHF-HELFLEHF-LELF. Thus, in general, this account would predict a primary effect of L2 English frequency, and a secondary effect of L1 French frequency of our cognate stimuli.

\section{Experiment}

\section{Method}

\section{Participants}

Nineteen participants (14 female; $20-27$ years of age, mean age $=22.3$ ) took part in the combined RT and ERP study. They were all right-handed as assessed by a French version of the Edinburgh Inventory for hand dominance (Oldfield, 1971), had normal or corrected-to-normal vision, and no history of neurological insult or language disability. They were all native speakers of French (L1) and English was their second language (L2). All participants were advanced students of English (i.e., at least in their 3rd year) at Aix-Marseille University, France. On average they started learning English at the age of $10 \quad(S D=1.8$; range $=7-14$ ). Participants filled in a questionnaire to assess their auto-evaluation of French and English language skills (the same one as used in Midgley, Holcomb, Van Heuven, \& Grainger, 2008). On a 7-point Likert scale, they rated their reading, speaking, and comprehension skills in their L1 French and their L2 English ( $1=$ unable to $7=e x-$ pert), as well as the frequency with which they read in the two languages $(1=$ rarely to $7=$ very often $)$. The overall average of self-reported language skills in French was 6.9 and in English 5.5. The frequency of reading was reported as 6.9 for French and 5.6 for English. Participants indicated that they used French on average $75 \%$ of their day and English 25\%. See Table 1 for more specific self-assessed competences.

\section{Stimuli}

Both RTs and ERPs were measured to 480 trials that consisted of 120 English-French identical cognates, 120 English control words, and 240 English-like nonwords. All words were selected from the CELEX database (Baayen, Piepenbrock, \& Van Rijn, 1993) and were correct English nouns. Lexical characteristics of the English reading of cognates and control words came from CELEX. Characteristics of the French reading of the cognate stimuli were derived from LEXIQUE 3.55 (New, Pallier, Ferrand, \& Matos, 2001). All word stimuli had noun as their most frequent syntactic category. When syntactically ambiguous, frequency measures were based on summed frequencies across all categories involved. All stimuli were between 3 and 9 letters of length. Table 2 gives an overview of stimulus characteristics in the various conditions of the experiment.

The 120 cognates were identical in orthography between English and French and they had a similar meaning in both languages. They all had a CELEX and LEXIQUE written lemma frequency of at least one per million and belonged to one of four categories. Thirty cognates were high frequency nouns in both English and French according to the CELEX (for the English reading) and LEXIQUE (for the French reading) lexical databases (HEHF; e.g., MESSAGE). Thirty cognates were high frequency in English and low frequency in French (HELF; e.g., MIXTURE). Thirty cognates were low frequency in English and high frequency in French (LEHF; e.g., ASSASSIN). Thirty cognates were low frequency in both English and French (LELF; e.g., ALTITUDE).

The 120 English control words, which did not exist in French and had a CELEX written lemma frequency of at least one per million, consisted of two categories. Sixty control words were high frequency English non-cognate nouns (HE; e.g., MISTAKE). Sixty control words were low frequency English non-cognate nouns (LE; e.g., BAKERY).

The 240 English-like nonword stimuli were derived from unused English nouns that were taken from CELEX. Nonwords were constructed by Wuggy (Keuleers \& Brysbaert, 2010) by changing one to four letters of these existing English nouns, in line with English orthotactics.

The total set of 480 stimuli was included in different randomized lists, which consisted of four blocks of 120 trials and were unique for each individual participant. No more than three words or nonwords were presented in sequence. In addition, no more than two cognates from the same category were presented in sequence.

Stimuli were manipulated at the Category level with respect to four measures: written log frequency of the lemma, written $\log$ frequency of the word form, written frequency of the lemma and written frequency of the word form. $t$-Tests showed that the groups of words that were assigned to a high frequency group (i.e., HE, the high frequency English reading of HEHF and HELF, as well as the high frequency French reading of HEHF and LEHF) did not differ significantly among one another on those four measures. The same held among the groups that were assigned low frequency (i.e., LE, the low frequency English reading of LEHF and LELF, as well as the low frequency French reading of HELF and LELF). All high frequency 
Table 1

Self assessed ratings (on a 7-point Likert scale) on L1 (French) and L2 (English) proficiency as well as the self-reported reading frequency in both languages. Standard deviations are indicated between parentheses.

\begin{tabular}{lllll}
\hline & Reading & Speaking & Reading frequency & General comprehension \\
\hline L1 French & $6.89(0.32)$ & $6.79(0.71)$ & $6.84(0.37)$ & $7(0)$ \\
L2 English & $5.66(0.82)$ & $5.47(0.96)$ & $5.32(1.11)$ & $5.55(1.04)$ \\
\hline
\end{tabular}

Table 2

Mean English (LogEN) and French (Log FR) log frequencies, mean English (MF EN) and French (MF FR) frequencies of the lemma corresponding to the stimuli (cognates and non-cognates), and mean number of letters (Nletters) for four groups of cognates (HEHF, HELF, LEHF and LELF) and two groups of control words (HE and LE)

\begin{tabular}{llllrrl}
\hline Category & $N$ & Log EN & Log FR & MF EN & MF FR & Nletters \\
\hline HEHF & 30 & 1.68 & 1.70 & 53.47 & 52.49 & 6.40 \\
HELF & 30 & 1.65 & 0.79 & 51.90 & 7.74 & 6.63 \\
HE & 60 & 1.68 & & 50.68 & & 6.05 \\
LEHF & 30 & 0.79 & 1.61 & 7.40 & 50.83 & 6.43 \\
LELF & 30 & 0.71 & 0.74 & 5.97 & 6.11 & 6.07 \\
LE & 60 & 0.75 & & 5.91 & & 6.05 \\
\hline
\end{tabular}

groups differed significantly from the low frequency groups on the four measures (for all $t$-tests: $p<.05$, Bonferroni correction applied). The four groups of cognates, the two groups of control words, and the nonwords neither differed significantly in word length as measured by the number of letters, nor on the number of orthographic neighbors.

Finally, we collected the phonetic transcription of our cognate stimuli from Celex (for the English reading) and Lexique (for the French reading), and calculated the IPAbased normalized Levenshtein distance (NLD) between the French and English phonetic reading (henceforth: phonological distance) of each cognate (see Appendix). A new substitution cost distribution was computed according the distinctive phonetic feature space of the IPA. This procedure is further described in Schepens et al. (2012) and Schepens, Dijkstra, Grootjen, and Van Heuven (submitted for publication). The mean phonological distance did not differ significantly across the four groups of cognate stimuli (all $t$-tests: $p>.05$ ).

\section{Procedure}

After completing informed consent, participants were seated in a comfortable chair at a distance of about one meter in front of a 22-in. CRT monitor in a sound attenuated, dimly illuminated room. All letter strings were presented in white letters on a black background in Courier New font (size 18). Before the start of the experiment, written instructions in English were presented on the screen. Participants were instructed that English strings of letters would appear on the screen, one after the other. They were asked to read every letter string carefully and to indicate by pressing a button with the left or right index finger whether the presented word was an English word (right finger) or not (left finger). They were asked to make their decisions as quickly and as accurately as possible. Also, they were asked to blink only when a specific symbol was presented on the screen.
Each trial started with the presentation of a fixation cross that remained on the screen for 200 ms. After the fixation cross, there was a blank of another $200 \mathrm{~ms}$, after which the stimulus appeared. The stimulus remained on the screen for $1300 \mathrm{~ms}$, followed by a symbol during which participants could blink their eyes for $2500 \mathrm{~ms}$. After this symbol, there was a blank again for $300 \mathrm{~ms}$ and then the next trial started. The response deadline was set to 1500 ms. Responses given after this deadline were considered as errors.

The experiment was presented in four blocks of 120 stimuli. Between the blocks participants could have a pause for as long as they wanted. The experiment lasted about $50 \mathrm{~min}$, cap-fitting excluded. Twelve test-items with the same characteristics as the stimuli preceded the main experiment as a practice set.

\section{Electrophysiological recording}

The electroencephalogram (EEG) was recorded continuously from 64 active $\mathrm{Ag}-\mathrm{AgCl}$ electrodes held in place on the scalp by an elastic cap (Electro-Cap Inc.) and placed according to the 10-10 International system (American Clinical Neurophysiology Society, 2006). Two additional electrodes, placed at both sides of $\mathrm{POz}$, were used for online referencing (see Schutter, Leitner, Kenemans, \& Van Honk, 2006; www.biosemi.com). In addition to the 66 scalp sites, four external electrodes were attached, one below the left eye (to monitor for vertical eye movement/ blinks), one on the lateral canthus to the right of the right eye (to monitor for horizontal eye movements/saccades), one over the left mastoid bone and one over the right mastoid bone. All electrode impedances were kept below $5 \mathrm{~K} \Omega$. The continuous EEG was digitized at $256 \mathrm{~Hz}$ and filtered offline (high-pass at $0.1 \mathrm{~Hz}$ and low-pass at $40 \mathrm{~Hz}$ ). All electrode sites were re-referenced offline to the average of the right and left mastoids. Epochs from $100 \mathrm{~ms}$ prestimulus onset to $900 \mathrm{~ms}$ post-stimulus onset were selected using EEGLAB software (Delorme \& Makeig, 2004).

\section{Results}

\section{Behavioral analyses}

Of the total raw dataset, $10.84 \%$ were errors (wrong responses and responses given after the RT deadline) and therefore removed. In addition, RTs outside the range of 2.5 standard deviations above the participant's mean were considered outliers and were excluded from the analyses (2.0\% of all data). Analyses of variance were performed on the mean RTs and mean error rate per experimental condition (repeated measures) in the participant analyses $\left(F_{1}\right)$, and on the mean RT and mean error rate per item in 
the item analyses $\left(F_{2}\right)$. All factors are within-participant factors in the participant analyses and between-item variables in the item analyses.

Table 3 shows the mean RT and the mean error rate for each category ( 4 groups of cognates and 2 groups of control words).

\section{$R T$ analyses}

Overall, mean RTs to words were $705 \mathrm{~ms}$ and to nonwords $812 \mathrm{~ms}$. Identical cognates $(M=694 \mathrm{~ms})$ were responded to faster than control words ( $M=726 \mathrm{~ms}$ ), which amounts to an overall cognate facilitation effect of $32 \mathrm{~ms}$.

To compare identical cognates with their control words, analyses of variance were performed on the mean RTs of the correct responses with cognate status (cognate vs. control) and English frequency (high vs. low) as independent variables. These analyses showed a significant main effect of cognate status, $F_{1}(1,18)=13.57, \quad p=.002 ; \quad F_{2}(1,236)=$ $20.70, p=.001$, implying that cognates were processed significantly faster than their matched controls. The analysis further showed a significant main effect of English frequency, $\quad F_{1}(1,18)=179.55, \quad p=.001 ; \quad F_{2}(1,236)=113.20$, $p=001$. Overall, high frequency English items (cognates and controls) were responded to significantly faster than low frequency English items ( $M=669 \mathrm{~ms}$ vs. $M=752 \mathrm{~ms}$ ). There was also a significant interaction between the two main factors, $F_{1}(1,18)=8.54, p=.009 ; F_{2}(1,236)=5.26$, $p=.023$, which reflects the fact that the cognate facilitation effect was larger for low frequency English cognates than for high frequency English cognates when both groups are compared with their matched control words (see Table 3).

To assess the effect of the manipulation of French frequency, analyses were performed on the RTs of the four groups of cognates only. These analyses, with English frequency (high vs. low) and French frequency (high vs. low) as factors, showed a significant main effect of English frequency, $F_{1}(1,18)=90.91, \quad p=.001 ; \quad F_{2}(1,116)=37.13$, $p=001$, and a significant main effect of French frequency in the by-participant analysis, $F_{1}(1,18)=4.65, p=.045$; $F_{2}(1,116)=3.23, p=.075$. Thus, cognates with a high English frequency reading $(M=659 \mathrm{~ms})$ were responded to significantly faster than cognates with a low English frequency reading $(M=729 \mathrm{~ms})$. Cognates with a high French frequency reading $(M=687 \mathrm{~ms})$ were responded to significantly faster than cognates with a low French fre-

Table 3

Mean RTs (in ms) and mean error rates (in percentages) per condition (HE, LE, HEHF, HELF, LEHF, LELF) in the current experiment. For comparison, the mean RTs (ELP RT) and mean error rates (ELP error rate) representing the corresponding (monolingual) data from the English Lexicon Project (ELP) are displayed. Standard deviations are indicated between parentheses.

\begin{tabular}{lllll}
\hline Condition & Mean RT & Mean error rate & ELP RT & ELP error rate \\
\hline HEHF & $653(77)$ & $0.88(1.51)$ & $631(48)$ & $2.20(2.22)$ \\
HELF & $666(74)$ & $1.05(1.59)$ & $638(56)$ & $2.50(3.44)$ \\
HE & $678(73)$ & $2.72(2.56)$ & $627(49)$ & $2.20(2.64)$ \\
LEHF & $722(86)$ & $22.46(15.31)$ & $724(70)$ & $13.01(14.55)$ \\
LELF & $737(72)$ & $11.75(9.19)$ & $705(84)$ & $9.87(10.40)$ \\
LE & $775(74)$ & $19.30(12.76)$ & $669(66)$ & $5.02(5.05)$ \\
\hline
\end{tabular}

quency reading $(M=701 \mathrm{~ms})$. There was no significant interaction effect between the two main factors $\left(F_{1}\right.$ and $\left.F_{2}<1\right)$.

\section{Error analyses}

Error analyses were performed on all responses participants gave in the lexical decision task. Overall, the mean error percentage to words was $10.02 \%$ and to nonwords $11.67 \%$. Slightly more errors were made on control words (11.01\%) compared to cognates (9.04\%).

To compare cognates with their control words, analyses of variance were performed on the percent error data with cognate status (cognate vs. control) and English frequency (high vs. low) as independent variables on the mean error rates. These analyses showed a significant main effect of English frequency, $F_{1}(1,18)=69.64, p=.001 ; F_{2}(1,236)=$ $119.53, p=.001$. The analysis did not show a significant main effect of cognate status, $F_{1}(1,18)=1.24, p=.28$; $F_{2}(1,236)=1.74, p=.19$. Overall, high frequency English items (cognates and controls) yielded significantly fewer errors than low frequency English items (1.84\% vs. $18.20 \%$ ). Cognates did not yield significantly fewer errors compared to their control words.

Additional analyses were performed on the mean error rates for the four groups of cognates only. These analyses, with English frequency (high vs. low) and French frequency (high vs. low) as factors, showed a significant main effect for English frequency, $F_{1}(1,18)=39.12, p=.001$; $F_{2}(1,116)=72.37, p=.001$, and a significant main effect for French frequency, $F_{1}(1,18)=20.73, \quad p=.001$; $F_{2}(1,116)=7.70, p=.006$. Thus, cognates with a high English frequency reading led to significantly fewer errors than cognates with a low English frequency reading $(0.96 \%$ vs. $17.11 \%)$. Cognates with a high French frequency reading yielded significantly more errors than cognates with a low French frequency reading ( $11.67 \%$ vs. $6.40 \%)$. There was a significant interaction effect between the two main factors, $F_{1}(1,18)=23.39, p=.001 ; F_{2}(1,18)=8.22, p=.005$. This interaction reflects the fact that an increase in English frequency of the cognates led to fewer errors whereas an increase in French frequency of the cognates led to more errors. Apparently, when cognates have a high French frequency in an English context, participants were more inclined to make errors (i.e., to judge the word as not being English). This interaction effect is carried by the low frequency English items (see Table 3).

\section{Post hoc analyses}

The cognate stimuli were orthographically identical and semantically similar, and no differences were found in phonological distance between the French and English reading when comparing the four groups of cognates (see Method). However, it could be the case that phonological distance influenced our RTs. So, in order to verify that differences in RTs cannot be explained by differences in the amount of phonological overlap across the French and English phonological reading of cognates, we examined the correlation between RT and phonological distance. A bivariate Spearman's correlation test showed no significant 
relationship between RT and the measure of phonological distance of our cognate stimuli, $r=.13, p=.16$.

Finally, we examined post hoc whether the cognate effects found in our study could be ascribed to uncontrolled stimulus characteristics. In order to attribute a cognate effect to knowledge of the non-target language in our bilingual participants, a monolingual group of participants should not show a cognate facilitation effect. Table 3 shows the RTs for all our word stimuli from the English Lexicon Project database (ELP: Balota et al., 2007). The monolingual RT data from the English Lexicon Project did not show a cognate facilitation effect comparing cognates and control words. $t$-Tests revealed that the RTs for the three groups of high frequency English stimuli (HE, HEHF, HELF) did not differ significantly from one another (all $p$-values >.32). Both groups of low frequency English cognates (LEHF, LELF) showed significantly slower RTs (both comparisons: $p<.05$ ) compared to the low frequency English control words (LE). Thus, monolinguals responded even slower to those cognates than to the control words. The monolingual RTs for the two groups of low frequency English cognates (LEHF, LELF) did not differ significantly $(p=.36)$. The different RTs for the English control words (HE, LE) underline that our frequency manipulation was successful. All in all, these data show that the cognate facilitation reported in our study cannot be explained by uncontrolled differences in our materials. If anything, the cognate effect for low frequency English words in our study would be underestimated, because of the opposite direction in the difference in the RTs and errors for the low frequency English cognates and control words in the ELP database compared to in our study.

\section{ERP analyses}

ERPs were calculated by averaging the EEG time-locked to a point $100 \mathrm{~ms}$ pre-stimulus onset and lasting until $900 \mathrm{~ms}$ after the onset of the stimulus. The $100 \mathrm{~ms}$ prestimulus period was used as a baseline. Trials defined as errors or outliers in the behavioral analyses, and trials containing ocular or muscular artifacts, were not taken into consideration in the averaging process. Of the total remaining dataset after removal of errors and outliers, $6.8 \%$ of the trials were removed due to artifacts. Separate ERPs were computed for every category in the experiment (i.e., four groups of cognates and two control categories). We applied an approach to data analysis in which the head surface is divided into five clusters (left anterior, LA; right anterior, RA; left posterior, LP; and right posterior, RP; and one cluster of ten vertical midline electrodes, see Fig. 1).

The mean amplitudes of the ERP waveforms for each condition per subject were entered into a repeated measures ANOVA. By-participant analyses were performed for each of $100 \mathrm{~ms}$ time-windows between stimulus onset and $900 \mathrm{~ms}$ post-onset. Similar to the behavioral analyses, we will first present analyses that tested for ERP correlates of the cognate facilitation effect. In those analyses English frequency, cognate status, and cluster were the independent variables. Secondly, we will present analyses limited to the four groups of cognates in order to test for effects of the frequency of the English and French reading of the

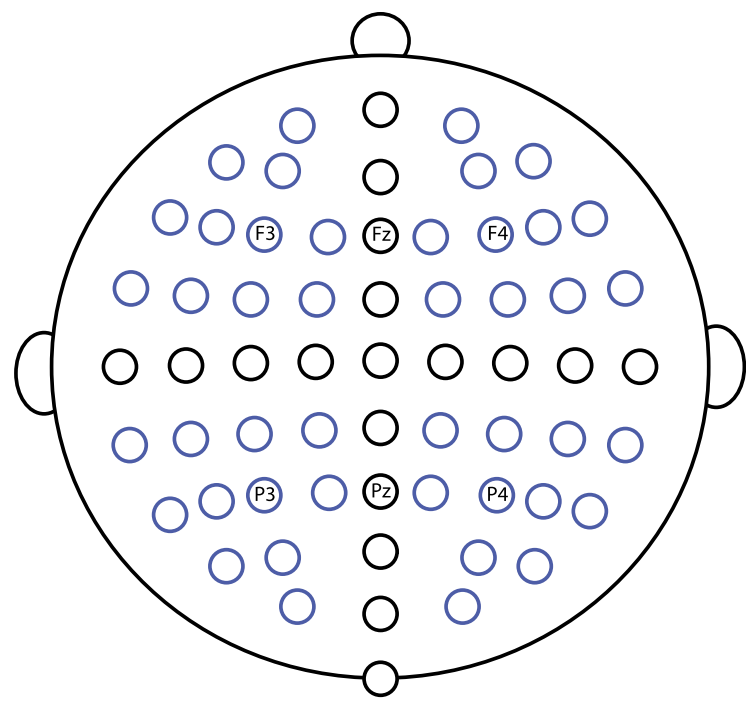

Fig. 1. Electrode montage. The four clusters used, in addition to the vertical midline cluster, in the analysis of the electrophysiological data are highlighted in blue. The electrode names in the figure refer to the electrode sites displayed in Figs. 2-6.

identical cognates. In the latter analyses English frequency, French frequency, and cluster were the independent variables. The Geisser and Greenhouse (1959) correction was applied to all analyses with more than one degree of freedom in the numerator (corrected $p$-values and degrees of freedom are reported). Unless stated differently, only significant results at the $5 \%$ level are reported.

\section{ERP cognate facilitation effects}

We first examined ERP correlates of the cognate facilitation effect seen in the behavioral data, by including the two groups of control words (HE and LE) and the two groups of cognates regardless of their French frequency (HE-cognates and LE-cognates) in an analysis with cognate status (cognate vs. control), English frequency (high vs. low), and cluster (LA, RA, LP, RP, Midline) as main factors. A significant main effect of English frequency was found in the 300-400 ms timewindow, $F(1,18)=12.45, p=.002$; the $400-500 \mathrm{~ms}$ timewindow, $F(1,18)=9.99, p=.005$; the $500-600 \mathrm{~ms}$ timewindow, $F(1,18)=35.44, p=.001$; and the $600-700 \mathrm{~ms}$ time-window, $F(1,18)=9.71, p=.006$. Further, a significant main effect of cognate status was found in the 600-700 ms time-window, $F(1,18)=11.82, p=.003$; the $700-800 \mathrm{~ms}$ time-window, $F(1,18)=18.66, p=.001$; and the $800-$ 900 ms time-window, $F(1,18)=5.04, p=.038$.

In addition, in the 400-500 ms time-window, we found a significant interaction effect between English frequency, cognate status, and cluster, $F(2,38)=3.26, p=.047$. We followed-up on this effect by performing separate analyses of variance for the five clusters in this particular time-window, with English frequency and cognate status as main factors. In the LA cluster, we did not find a main effect of English frequency or cognate status. In the RA cluster, we found a significant main effect of English frequency, $F(1,18)=5.49, p=.031$. In the LP cluster we found a significant main effect of English frequency, $F(1,18)=12.37$, 
$p=.002$, and a significant main effect of cognate status, $F(1,18)=5.63, p=.029$. In the RP cluster we found a significant main effect of English frequency, $F(1,18)=12.11$, $p=.003$. Finally, in the Midline cluster we found a significant main effect of English frequency, $F(1,18)=11.71$, $p=.003$. In none of these analyses an interaction effect between English frequency and cognate status was found.

The main effect of English frequency reflected that the words with a low English frequency yielded a significantly more negative going wave than the words with a high English frequency. Fig. 2 shows the topographic maps of voltage differences between the high frequency English and the low frequency English words, and the corresponding grand average waveforms. The main effect of cognate status in the 400-500 ms time-window in the left posterior quadrant reflected that control words yielded a significantly more negative going wave compared to cognates. The larger effect of cognate status in time-windows 600$900 \mathrm{~ms}$ after stimulus onset reflected a more positive going wave for control words compared to cognates. Fig. 3 shows the topographic maps of voltage differences between the cognates and the control words, and the grand average waveforms for these effects.

\section{ERP cognate frequency effects}

Secondly, we performed analyses of variance on the four groups of cognates only, to test whether the English and the French frequency contributed equally to cognate processing.

An analysis on the four groups of cognates with English frequency, French frequency, and cluster as independent variables yielded a significant main effect of English frequency, in the 300-400 ms time-window, $F(1,18)=11.04$, $p=.004$; the $400-500 \mathrm{~ms}$ time-window, $F(1,18)=5.56$, $p=.030$; the $500-600 \mathrm{~ms}$ time-window, $F(1,18)=9.65$, $p=.006$; and the $600-700 \mathrm{~ms}$ time-window, $F(1,18)=$ $6.73, p=.018$. In addition, a significant interaction effect between English frequency, French frequency, and cluster was found in the 400-500 ms time-window, $F(2,33)=$ $4.51, p=.021$. We followed-up on this effect by performing separate analyses of variance for the five clusters in this particular time-window, with English frequency and French frequency as main factors. In the LA cluster, we did not find a significant effect. In the RA cluster, we found a significant main effect of French frequency, $F(1,18)=6.26, p=.022$. In the LP cluster, we found a significant main effect of English frequency, $F(1,18)=7.18$, $p=.012$. In the RP cluster, we also found a significant main effect of English frequency, $F(1,18)=7.75, p=.012$. Finally, in the Midline cluster we also found a significant main effect of English frequency, $F(1,18)=7.71, p=.012$.

In general, the main effects of English frequency reflected that cognates with a low English frequency yielded a more negative going wave than cognates with a high English frequency. Fig. 4 shows the topographic maps and grand average waveforms of high frequency English cognates compared to low frequency English cognates, collapsed over their French frequency. The right anterior main effect of French frequency in the 400-500 ms time-window reflected that cognates with a low French frequency yielded a more negative going wave than cognates with a high French frequency. Fig. 5 shows the topographic maps and grand average waveforms of high frequency French cognates compared to low frequency French cognates, collapsed over their English frequency.

Finally, in order to test the predictions made by the three theoretical accounts, we performed a repeated measures linear contrast analysis entering the four groups of cognates separately into this analysis with condition (i.e., the four groups of cognates) and cluster as independent variables. This analysis compared every cognate condition to the condition that was entered into the model previously. Table 4 shows the outcome of the linear contrasts between these groups of cognates. The critical point in
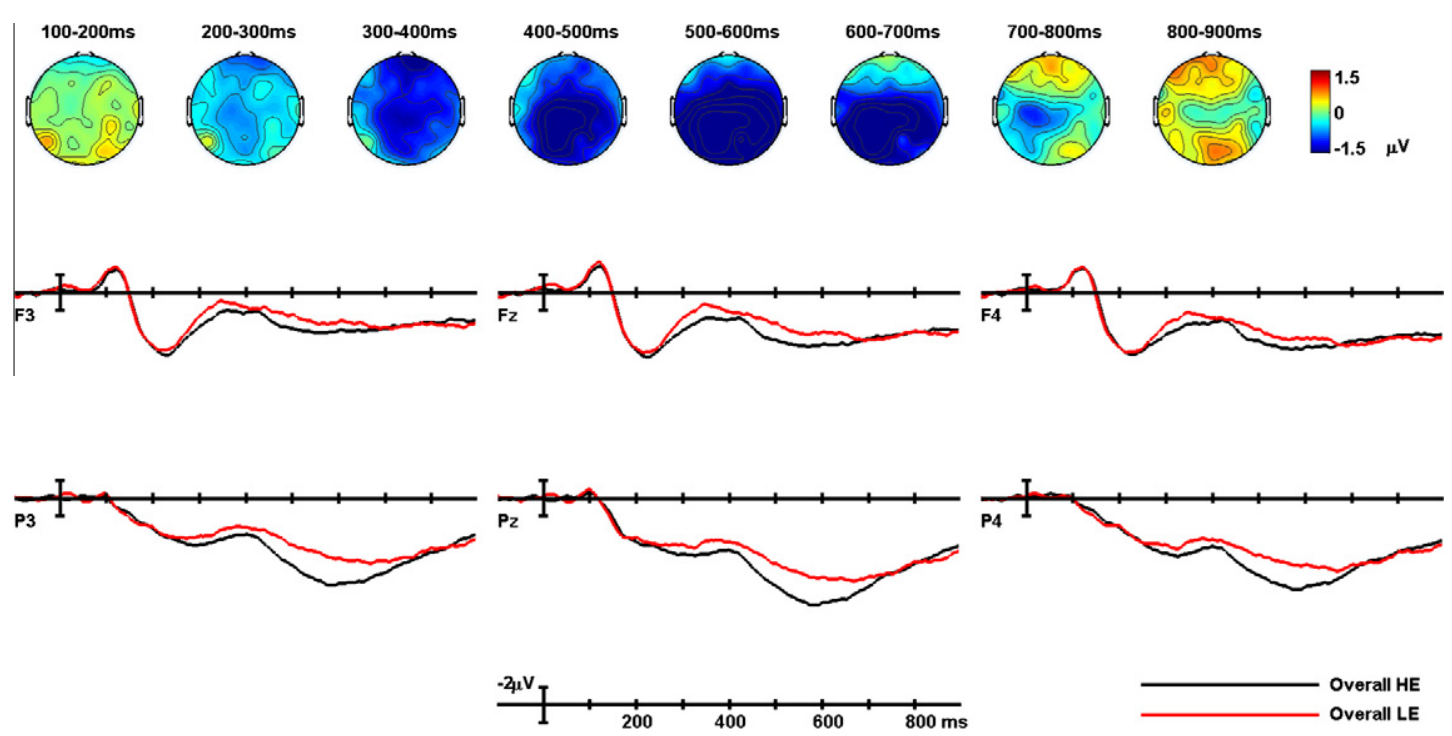

Fig. 2. Topographic maps of voltage differences between high frequency English stimuli (irrespective of their cognate status) and low frequency English stimuli (irrespective of their cognate status), for $100 \mathrm{~ms}$ time-windows, and the corresponding grand average waveforms. Negative values are plotted up. 

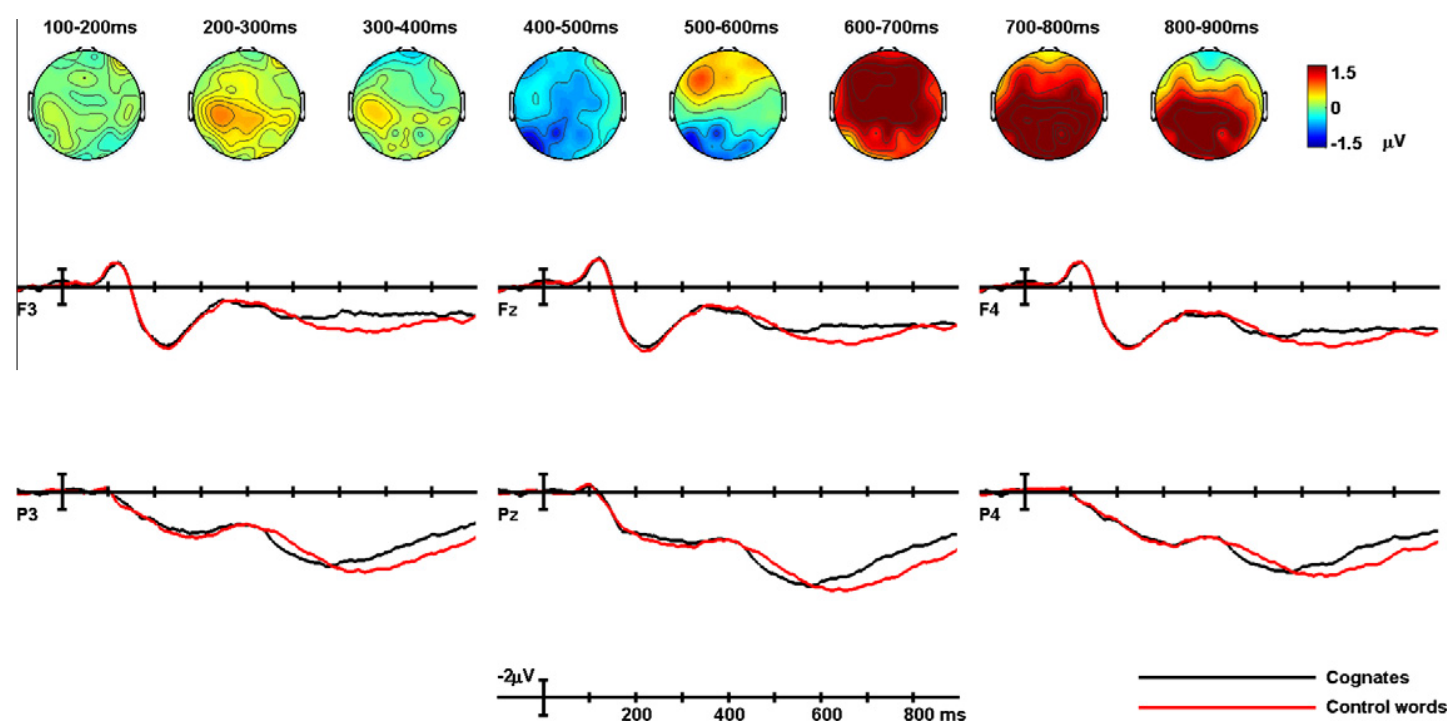

Fig. 3. Topographic maps of voltage differences between cognates (irrespective of their French and English frequency) and control words (irrespective of their English frequency), for $100 \mathrm{~ms}$ time-windows, and the corresponding grand average waveforms. Negative values are plotted up.
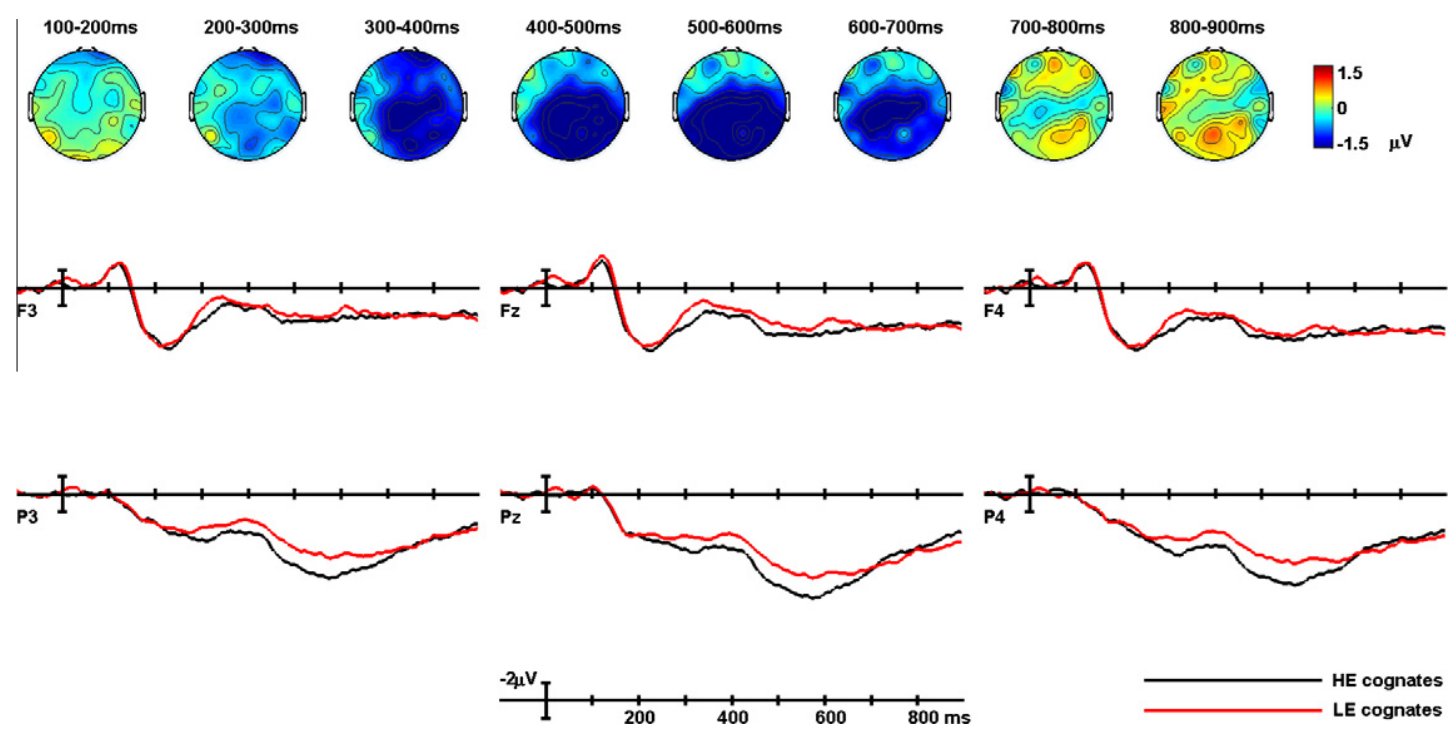

Fig. 4. Topographic maps of voltage differences between high frequency English cognates (irrespective of their French frequency) and low frequency English cognates (irrespective of their French frequency), for $100 \mathrm{~ms}$ time-windows, and grand average waveforms for six electrode sites. Negative values are plotted up.

which the three accounts differ is the directionality of the N400 amplitude difference in the comparison of the LEHF and the HELF cognates. Fig. 6 presents the ERP wave-forms and corresponding topographic plots of this comparison. Analysis and visual inspection of the waveforms showed a significantly more negative going $\mathrm{N} 400$ for the LEHF condition compared to the HELF condition. In addition, a significant condition $\times$ cluster interaction effect was found between the HEHF cognates and the HELF cognates, which denoted a significantly more negative going N400 for HELF cognates compared to HEHF cognates in the right anterior cluster. No significant effects were found in the contrast between LEHF and LELF cognates.

\section{Discussion}

RTs and ERPs were recorded while late French-English bilinguals performed a lexical decision task in their L2 (English). Orthographically identical cognates were selected that varied with respect to their English and French frequencies of usage, and their processing was compared 

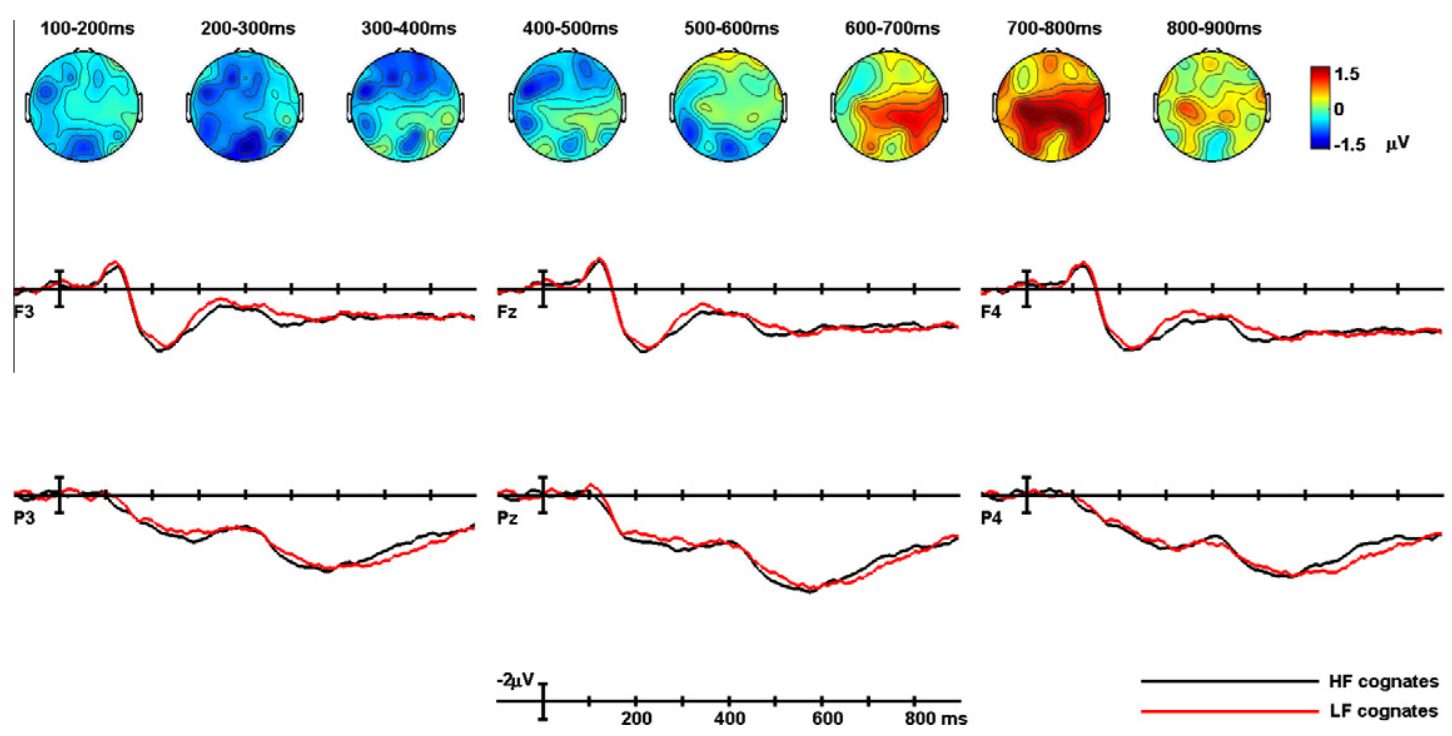

Fig. 5. Topographic maps of voltage differences between high frequency French cognates (irrespective of their English frequency) and low frequency French cognates (irrespective of their English frequency), for $100 \mathrm{~ms}$ time-windows, and grand average waveforms for six electrode sites. Negative values are plotted up.

Table 4

Outcome of the repeated measures linear contrast analyses comparing HEHF to HELF, HELF to LEHF, and LEHF to LELF. F-values and significance levels are provided for the main effect of Condition and the interaction effect between Condition and Cluster (LA, RA, LP, RP, Midline). In addition, follow-up linear contrasts are provided for each individual cluster separately.

\begin{tabular}{lllll}
\hline & $300-400$ & $400-500$ & $500-600$ & $600-700$ \\
\hline HEHF vs. HELF & & & & \\
Condition $\times$ Cluster & $3.72^{\mathrm{t}}$ & $8.02^{*}$ & $\mathrm{~ns}$ & $\mathrm{~ns}$ \\
Condition & $\mathrm{ns}$ & $\mathrm{ns}$ & $\mathrm{ns}$ & $\mathrm{ns}$ \\
LA & $\mathrm{ns}$ & $\mathrm{ns}$ & $\mathrm{ns}$ & $\mathrm{ns}$ \\
RA & $\mathrm{ns}$ & $5.21^{*}$ & $\mathrm{~ns}$ & $\mathrm{~ns}$ \\
LP & $\mathrm{ns}$ & $\mathrm{ns}$ & $\mathrm{ns}$ & $\mathrm{ns}$ \\
RP & $\mathrm{ns}$ & $\mathrm{ns}$ & $\mathrm{ns}$ & $\mathrm{ns}$ \\
Midline & $\mathrm{ns}$ & $\mathrm{ns}$ & $\mathrm{ns}$ & $\mathrm{ns}$ \\
HELF vs. LEHF & & & & \\
Condition $\times$ Cluster & $11.18^{* *}$ & $14.39^{* * *}$ & $4.57^{*}$ & $\mathrm{~ns}$ \\
Condition & $\mathrm{ns}$ & $\mathrm{ns}$ & $4.62^{*}$ & $8.57^{* *}$ \\
LA & $\mathrm{ns}$ & $\mathrm{ns}$ & $\mathrm{ns}$ & $\mathrm{ns}$ \\
RA & $\mathrm{ns}$ & $\mathrm{ns}$ & $\mathrm{ns}$ & $3.85^{\mathrm{t}}$ \\
LP & $\mathrm{ns}$ & $4.36^{\mathrm{t}}$ & $8.11^{*}$ & $9.34^{* *}$ \\
RP & $3.91^{\mathrm{t}}$ & $\mathrm{ns}$ & $5.73^{*}$ & $11.70^{* *}$ \\
Midline & $\mathrm{ns}$ & $\mathrm{ns}$ & $5.90^{*}$ & $8.75^{* *}$ \\
LEHF $v s$. LELF & & & & \\
Condition $\times$ Cluster & $\mathrm{ns}$ & $\mathrm{ns}$ & $3.56^{\mathrm{t}}$ & $\mathrm{ns}$ \\
Condition & $\mathrm{ns}$ & $\mathrm{ns}$ & $\mathrm{ns}$ & $\mathrm{ns}$ \\
LA & $\mathrm{ns}$ & $\mathrm{ns}$ & $\mathrm{ns}$ & $\mathrm{ns}$ \\
RA & $\mathrm{ns}$ & $\mathrm{ns}$ & $\mathrm{ns}$ & $3.90^{\mathrm{t}}$ \\
LP & $\mathrm{ns}$ & $\mathrm{ns}$ & $\mathrm{ns}$ & $\mathrm{ns}$ \\
RP & $\mathrm{ns}$ & $\mathrm{ns}$ & $\mathrm{ns}$ & $4.37^{\mathrm{t}}$ \\
Midline & $\mathrm{ns}$ & $\mathrm{ns}$ & $\mathrm{ns}$ & $\mathrm{ns}$ \\
\hline
\end{tabular}

ns $=$ not significant.

${ }^{*} p<.05 ;{ }^{* *} p<.01 ;{ }^{* * *} p<.001 ;{ }^{\mathrm{t}} p<.075$.

to matched English control words. Cognates were responded to faster than non-cognate control words, and high English frequency words were responded to faster than low English frequency words. Further analysis of the RTs on the identical cognates revealed faster responses to items with higher English and/or French frequencies. The cognate facilitation effect was larger for cognates with a low English frequency than for cognates with a high English frequency. Fewer errors were obtained for cognates compared to control words and for words with a high English frequency compared to those with a low English frequency. One interesting finding was that the LEHF cognates yielded a relatively high percentage of errors relative to the other groups of cognates.

The electrophysiological data showed an overall N400 cognate facilitation effect in parietal regions and a widely distributed overall effect of English frequency in the N400 time-window. Also, cognates yielded a late positivity (600-900 ms) compared to control words. In addition, when comparing the four groups of cognates, we found a long and wide-spread N400 effect of English frequency (300-700 ms after word onset) and a shorter, anterior N400 effect of French frequency (400-500 ms after word onset). Critically, the cognates with a low L2 English frequency and a high L1 French frequency yielded a significantly more negative going N400 compared to the cognates with a high L2 English frequency and a low L1 French frequency.

Our behavioral data are in line with a wealth of previous studies showing that cognates are processed more quickly than control words (e.g., Caramazza \& Brones, 1979; Cristoffanini et al., 1986; Davis et al., 2010; De Groot \& Nas, 1991; Dijkstra et al., 1998, 1999, 2010; Font, 2001; Lemhöfer \& Dijkstra, 2004; Lemhöfer et al., 2004; SánchezCasas et al., 1992; Van Hell \& Dijkstra, 2002; Voga \& Grainger, 2007). However, our study is the first to show, both behaviorally and electrophysiologically, that not only the frequency of the target reading of the cognate (in this case 

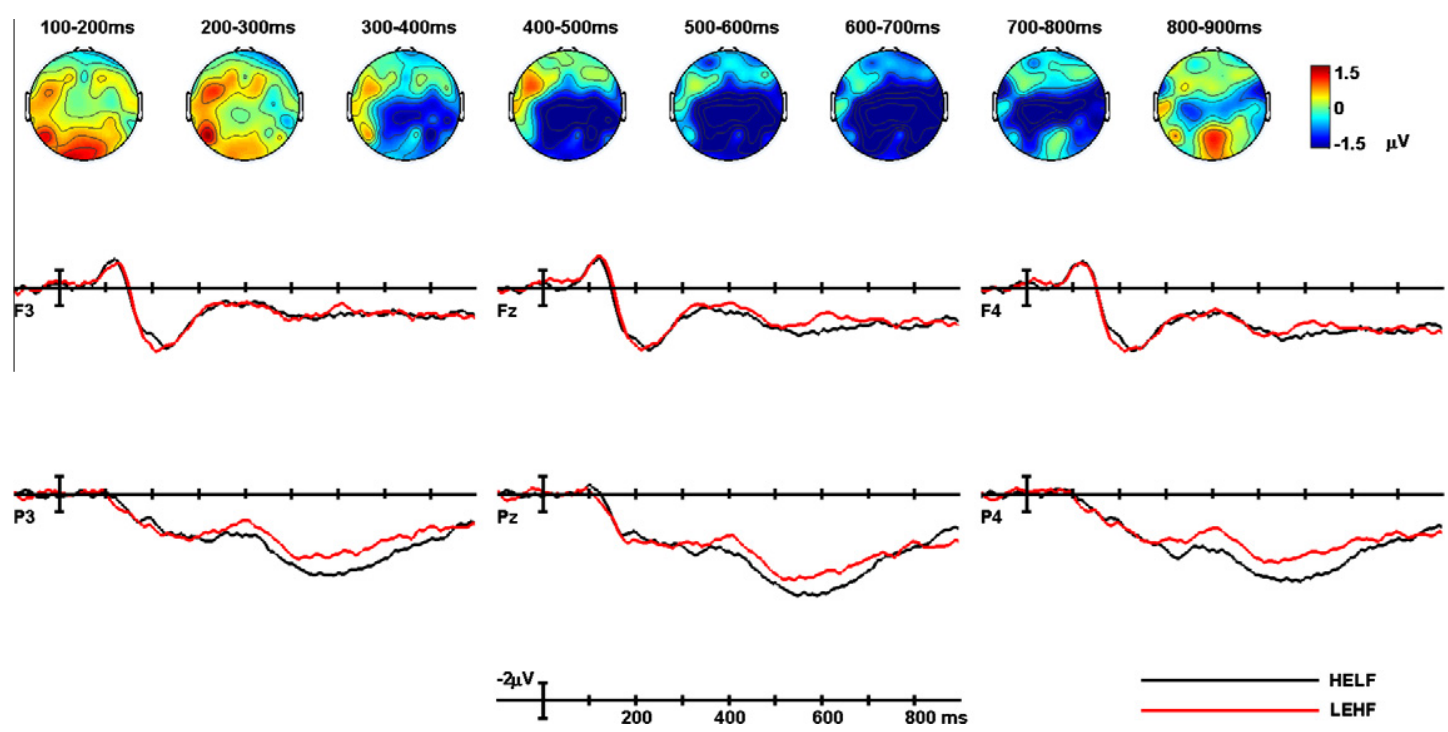

Fig. 6. Topographic maps of voltage differences between LEHF cognates and HELF cognates, for 100 ms time-windows, and grand average waveforms for six electrode sites. Negative values are plotted up.

English) but also the frequency of the non-target reading (in this case French) affects cognate processing. Furthermore, cognate effects in the RTs were larger for identical cognates with a low frequency target reading compared to a high frequency target reading. In other words, an identical cognate with a low English frequency benefits relatively more from its French reading than a cognate with a high English frequency. This is the first study to show this finding for cognate words, because no previous studies have orthogonally manipulated the frequency of both readings of cognate stimuli. Our findings thus support a claim made by Gollan, Montoya, Cera, and Sandoval (2008), that an increase in bilinguals' use of a word leads to a smaller frequency effect (see also Duyck, Vanderelst, Desmet, \& Hartsuiker, 2008).

Our electrophysiological data confirm a recent finding by Midgley et al. (2011) in showing overall cognate facilitation in the N400 time-window comparing cognates to matched control words. In addition, we found a late positive effect, 600-900 ms after stimulus onset, that can be identified as a P600 effect. Midgley et al. (2011) do not report such a finding. We believe that this late effect is related to the lexical decision participants had to make in our study. In the study by Midgley et al. (2011), participants performed a semantic categorization task, in which the English and French reading of cognate words did not relate to the task. In the current study, participants performed a lexical decision task in which they saw only English words. However, the cognate stimuli also had a French reading which may have led to a conflict that was reflected in the P600 component for cognates but not for control words.

The N400 effect for cognates compared to control words in bilingual L2 word recognition, as reported by Midgley et al. (2011), surprisingly had an anterior distribution.
Canonically, N400 effects have a more centro-parietal distribution (see Kutas \& Federmeier, 2011). In the current study, we found such a centro-parietal distribution for the effect of L2 English frequency of cognate words, whereas the L1 French frequency of cognates led to a more anterior $\mathrm{N} 400$ effect. This raises the interesting possibility that the anterior cognate N400 effect reported by Midgley et al. (2011) could have been driven by the L1 frequency of their cognate stimuli. Our study shows that the L1 frequency and L2 frequency of cognate words lead to separable N400 effects that are of a different duration and display a different scalp distribution.

The theoretical importance of these findings will now be discussed in terms of the three positions on identical cognates presented in the introduction.

\section{The representation and processing of identical cognates}

The first theoretical account that we put forward, the shared-morpheme view, proposes that identical cognates have one shared morphological representation. It explains cognate facilitation in terms of cumulative frequency. Because this shared morphological representation would be activated by cognates in both languages of the bilingual, while non-cognates activate their morphological representation in only one language, cognates would be processed more quickly than matched control words. This view attributes a higher importance to the French frequency of the cognates than to their English frequency, because our late French-English bilinguals encountered and used the identical cognates much more often in their L1 than in their L2. On the basis of our behavioral data, the shared-morpheme account can be rejected. In fact, the shared-morpheme view as a whole is disconfirmed, because HELF cognates were processed more quickly than LEHF cognates. Thus, 
participants relied more on the frequency of the cognates in the target language (English) than on their frequency in their native language (French), whereas the shared-morpheme view predicted the opposite. In addition, this view predicted a more negative going N400 for HELF cognates compared to LEHF cognates. Our data showed the opposite pattern.

Like the shared-morpheme view, the second theoretical account, the form-overlap view, proposed a shared representation for identical cognates by introducing a common orthographic representation and a shared semantic representation. This account also explained cognate facilitation in terms of cumulative frequency: Bilinguals encounter cognates more often than other words that exist in only one language; they therefore have stronger links between their orthographic and semantic representation; and as such they are processed more quickly than control words. However, because this account also predicts cumulative effects of the cognates' frequencies across languages, it does not account for our data.

The third theoretical account, termed the two-morpheme view, argues that identical cognates, although having an identical form, are represented twice in the bilingual lexicon at the phonological and morphological level. In an English language context, participants then use the representations related to the target language (English) for their lexical decisions. This view leads to the prediction that in our experiment the English frequency of identical cognates would be more important than their French frequency. Indeed, this account predicted the hierarchy that appeared in the RT data across our frequency conditions. In addition, it predicted a more negative going N400 for LEHF cognates compared to HELF cognates. This prediction was also confirmed. Thus, it seems that our data are mostly in line with the two-morpheme view, and disconfirm the form-overlap and shared-morpheme views.

There are other theoretical and empirical arguments against the shared-morpheme view. As a theoretical argument, the notion of cumulative frequency across languages is complex. Gollan and colleagues (e.g., Gollan \& Silverberg, 2001; Gollan et al., 2008) argued that the total time a bilingual speaks is distributed over two languages. Although French-English bilinguals may retrieve an identical cognate in total over the two languages more often than a matched non-cognate, the number of times they use the cognate in L1 should decrease the more they use their L2. As a consequence, frequency counts like CELEX and LEXIQUE that are based on word usage by L1 speakers do not provide adequate frequency measures for L1 and L2 due to the distributed use of L1 and L2 in the life of bilinguals. Note that this argument holds also against the form-overlap view.

Furthermore, as an empirical argument, there are several previous studies rejecting the shared-morpheme view. For instance, if cognates share one morphemic representation across languages, no RT-difference is expected for the same target word in cognate priming and in priming by a morphologically related non-cognate matched prime. In contrast to this hypothesis, in a Greek-English lexical decision study, Voga and Grainger (2007) observed a significantly larger masked priming effect on English (L2) targets preceded by cognates relative to morphemes. More recently, Dijkstra et al. (2010) also obtained evidence against the shared-morpheme view, by showing that RTs to cognates processed by Dutch-English bilinguals in an English lexical decision task decrease for cognates with a higher cross-linguistic orthographic similarity. The shared-morpheme view would not predict such a difference in processing for identical and non-identical cognates, because in both cases, the two readings of a cognate would share their morphological representation and therefore would benefit in a similar way from it.

It should be noted that the current study investigated late, unbalanced bilinguals. Two recent studies that have been interpreted in the light of the shared-morpheme account investigated highly proficient, balanced bilinguals (Davis et al., 2010; Sánchez-Casas \& García-Albea, 2005). However, this was not the case for earlier studies proposing the shared-morpheme view (e.g., Cristoffanini et al., 1986; Kirsner et al., 1993; Lalor \& Kirsner, 2000) The present study cannot exclude the possibility that the sharedmorpheme account reflects the processing of cognates by balanced bilinguals. In addition, the form-overlap account is partly based on research investigating different script bilinguals (Voga \& Grainger, 2007). Therefore, the formoverlap account might best explain cognate processing by that particular type of bilingual.

To summarize, an evaluation of the three theoretical views on identical cognate representation in the light of our collected data provides support mainly for the two-morpheme view. We argued that, most likely, the two cognate representations are distinguished not only at the phonological but also at the morphological level. Each of the two readings of an identical cognate has a language-specific morphological representation in each language. Furthermore, our results indicate that the bilingual processing of identical cognates is sensitive to task and language context. In the English context of our L2 lexical decision task, the English morphological representation played the most important role in processing, because the decision had to be based on English as the relevant target language.

Why would identical cognates, although identical in orthographic form and meaning, have developed not only two phonological but also two morphological representations? One reason could be that identical cognates in different languages can have different plural forms (e.g., the identical cognate FILM which has the plural form FILMS in English but FILME in German). The information about the plural form in a specific language would be related to the cognate morpheme in that language only, facilitating the use of the correct plural suffix in the language one is using. Similarly, identical cognates can also have different gender across languages and belong to different syntactic categories.

One other explanation for the development of two representations for identical cognates is related to the 
different phonology that both readings of a cognate can have. The fact that identical cognates can have a different phonological form across languages has not received much attention in previous studies explaining the processing and representation of identical cognates. However, an account proposing two phonological representations is not incompatible with our results, as reflected in the finding that the high French frequency of LEHF cognates speeded up lexical decision, but also led to more errors for this category compared to control words. A higher non-target (French) frequency of cognates could lead to a stronger effect of its phonology in the lexical decision task in English. The quick activation of French phonology would then speed up the RTs for such cognates compared to matched control words, because the semantic representation of the cognates would be activated by two phonological (and, in line with the two-morpheme view, morphological) representations, relative to only one phonological and/or morphological representation for the control words existing in one language only. At the same time, a high French frequency would also increase the error rates for these words, because participants could link French language status to a no-response in the English lexical decision task (cf. Dijkstra, 2005).

Although in the current study we did not contrast the orthographic and phonological overlap of cognate stimuli, one may have expected an effect of the degree of phonological overlap on our dependent variables. An increase in phonological overlap of the two readings of a cognate led to faster reaction times in a previous study on Dutch-English bilinguals (Dijkstra et al., 2010; see also Schwartz, Kroll, \& Diaz, 2007). Furthermore, effects of phonology could have arisen in early ERP time-windows (Holcomb \& Grainger, 2006). We did not find such effects. This may be related to the specific language pair under investigation. The degree of phonological overlap is much larger for Dutch-English cognates than for the currently used French-English cognates, which could have driven the effects in Dijkstra et al. (2010). Also, the participants in Dijkstra et al. (2010) were more proficient in their L2 English than the participants in the current study. A higher L2 proficiency may lead to a larger chance of detecting an effect of phonological overlap.

We note that identical cognates may have two morphological representations because, in the case of late bilinguals, identical cognates have generally been acquired in different environments and situations. This explanation is in line with a claim made by Baayen (2010) that contextual learning during past experience can underlie the processes of current proficient reading. Following McDonald and Shillcock (2001), Baayen argues that the context in which a word is learnt is an important factor with respect to how it is processed and represented. Because late bilinguals generally learn their native language in a different context than their second language (at home vs. at school/abroad), two representations with language dependent morphosyntactic characteristics may develop even in spite of their shared orthography and semantics. Note that the L1 and L2 contexts in which the two readings of identical cognates are used may differ, because late bilinguals may use their L2 only in particular contexts (e.g., in the classroom or when reading a foreign book).

To conclude, our study was the first to systematically manipulate the frequency of both readings of cognates. On the basis of the empirical findings, several conclusions could be drawn concerning the processing and representation of identical cognates. First, both behaviorally and electrophysiologically, both readings of cognates were found to affect cognate processing. Second, our behavioral data showed a larger L2 (English) cognate facilitation for cognates with a low L2 frequency relative to those with a high L2 frequency. Especially cognates with a low frequency L2 reading and a high frequency L1 (French) reading resulted in large facilitation effects.

Finally, a two-morpheme view was found to account best for the collected behavioral and electrophysiological data. To explain the observed differential frequency effects of the two readings of identical cognates, we proposed two language-specific morphemic and phonological representations. The two morphemic representations are characterized by their own language-specific frequency and can be linked to language-specific plural markers, gender, and syntactic category. The different social situations in which identical cognates are learnt by late bilinguals (at home for L1 vs. at school/abroad for L2) are another argument for why identical cognates may be represented twice in the bilingual brain. Both behavioral and electrophysiological data support this representation of cognates in the bilingual mental lexicon.

\section{Acknowledgments}

The reported research was conducted while the first author was in Marseille at the LPC. We thank Sally Andrews, Albert Costa, and two anonymous reviewers for valuable comments on earlier versions of this paper. We thank Maria Ktori and Stéphane Dufau for help in setting up the experiment and Olivier Sasburg for help in selection of the stimuli.

\section{Appendix A}

Stimuli used in the experiment. For all stimuli, the English $\log$ frequency is provided $(\log \mathrm{E})$, as well as the corresponding raw lemma frequency (f-ENG), the number of letters (Letters), and English neighbors (NbE) as derived from Celex. In addition, for all cognate stimuli, the French $\log$ frequency is provided (Log FR), as well as the corresponding French raw lemma frequency (f-FR) and the number of French neighbors (NbFR) as derived from Lexique, and the normalized phonological Levenshtein distance (NLD). 


\begin{tabular}{|c|c|c|c|c|c|c|c|c|c|}
\hline Category & Stimulus & $\log E$ & Log FR & f-ENG & f-FR & Letters & NbFR & $\mathrm{NbE}$ & NLD \\
\hline \multirow[t]{30}{*}{ HEHF } & Accent & 1.48 & 1.66 & 30 & 45.54 & 6 & 0 & 2 & 0.75 \\
\hline & Angle & 1.51 & 1.76 & 32 & 57.64 & 5 & 3 & 1 & 0.79 \\
\hline & Article & 1.81 & 1.70 & 64 & 50.34 & 7 & 1 & 0 & 0.85 \\
\hline & Avenue & 1.45 & 1.71 & 28 & 51.21 & 6 & 1 & 1 & 0.76 \\
\hline & Base & 1.93 & 1.67 & 85 & 47.16 & 4 & 14 & 12 & 0.82 \\
\hline & Contact & 1.99 & 1.82 & 98 & 65.47 & 7 & 2 & 0 & 0.83 \\
\hline & Costume & 1.51 & 1.76 & 32 & 57.64 & 7 & 2 & 0 & 0.85 \\
\hline & Courage & 1.53 & 1.85 & 34 & 70.34 & 7 & 2 & 0 & 0.75 \\
\hline & Cousin & 1.53 & 1.95 & 34 & 89.93 & 6 & 2 & 0 & 0.63 \\
\hline & Crime & 1.81 & 1.65 & 65 & 45.07 & 5 & 8 & 4 & 0.93 \\
\hline & Culture & 1.92 & 1.45 & 83 & 28.51 & 7 & 0 & 1 & 0.81 \\
\hline & Danger & 1.99 & 1.74 & 97 & 55.27 & 6 & 4 & 5 & 0.67 \\
\hline & Date & 1.94 & 1.80 & 87 & 62.97 & 4 & 11 & 13 & 0.82 \\
\hline & Fortune & 1.59 & 1.71 & 39 & 51.49 & 7 & 1 & 0 & 0.85 \\
\hline & Fruit & 1.85 & 1.81 & 71 & 64.05 & 5 & 2 & 0 & 0.70 \\
\hline & Garage & 1.40 & 1.38 & 25 & 24.12 & 6 & 3 & 0 & 0.90 \\
\hline & Illusion & 1.40 & 1.68 & 25 & 47.36 & 8 & 1 & 1 & 0.73 \\
\hline & Incident & 1.60 & 1.50 & 40 & 31.62 & 8 & 1 & 0 & 0.72 \\
\hline & Instinct & 1.46 & 1.55 & 29 & 35.27 & 8 & 0 & 0 & 0.70 \\
\hline & Message & 1.97 & 1.63 & 93 & 42.57 & 7 & 1 & 1 & 0.79 \\
\hline & Mission & 1.56 & 1.69 & 36 & 48.45 & 7 & 1 & 1 & 0.71 \\
\hline & Nation & 2.09 & 1.67 & 123 & 47.23 & 6 & 4 & 2 & 0.64 \\
\hline & Passion & 1.58 & 1.94 & 38 & 87.64 & 7 & 0 & 0 & 0.71 \\
\hline & Portrait & 1.49 & 1.75 & 31 & 55.60 & 8 & 0 & 0 & 0.77 \\
\hline & Prince & 1.60 & 2.01 & 40 & 101.22 & 6 & 1 & 1 & 0.86 \\
\hline & Religion & 1.72 & 1.54 & 53 & 35.07 & 8 & 0 & 0 & 0.73 \\
\hline & Solution & 1.88 & 1.64 & 76 & 43.51 & 8 & 0 & 0 & 0.76 \\
\hline & Statue & 1.38 & 1.64 & 24 & 43.85 & 6 & 3 & 1 & 0.90 \\
\hline & Taxi & 1.57 & 1.67 & 37 & 46.82 & 4 & 6 & 0 & 0.92 \\
\hline & Vision & 1.74 & 1.62 & 55 & 41.82 & 6 & 0 & 0 & 0.71 \\
\hline \multirow[t]{30}{*}{ HELF } & Addition & 1.83 & 0.98 & 67 & 9.53 & 8 & 1 & 1 & 0.71 \\
\hline & Argument & 2.12 & 1.26 & 132 & 18.18 & 8 & 0 & 0 & 0.66 \\
\hline & Budget & 1.58 & 0.82 & 38 & 6.62 & 6 & 0 & 1 & 0.61 \\
\hline & Campus & 1.34 & 0.21 & 22 & 1.62 & 6 & 3 & 0 & 0.81 \\
\hline & Cancer & 1.95 & 0.98 & 89 & 9.46 & 6 & 6 & 4 & 0.84 \\
\hline & Concept & 1.79 & 0.51 & 62 & 3.24 & 7 & 1 & 2 & 0.86 \\
\hline & Corridor & 1.61 & 1.10 & 41 & 12.5 & 8 & 0 & 0 & 0.87 \\
\hline & Cycle & 1.58 & 0.76 & 38 & 5.81 & 5 & 1 & 0 & 0.90 \\
\hline & District & 1.67 & 0.23 & 47 & 1.69 & 8 & 0 & 1 & 0.95 \\
\hline & Doctrine & 1.36 & 0.89 & 23 & 7.77 & 8 & 1 & 0 & 0.94 \\
\hline & Document & 1.76 & 1.20 & 57 & 16.01 & 8 & 0 & 0 & 0.71 \\
\hline & Festival & 1.40 & 0.72 & 25 & 5.27 & 8 & 0 & 0 & 0.87 \\
\hline & Fiction & 1.20 & 0.71 & 16 & 5.14 & 7 & 3 & 2 & 0.76 \\
\hline & Finance & 1.68 & 1.06 & 48 & 11.48 & 7 & 1 & 0 & 0.83 \\
\hline & Golf & 1.52 & 0.86 & 33 & 7.30 & 4 & 1 & 3 & 0.95 \\
\hline & Impact & 1.64 & 0.40 & 44 & 2.50 & 6 & 0 & 1 & 0.85 \\
\hline & Invasion & 1.49 & 1.05 & 31 & 11.22 & 8 & 0 & 0 & 0.59 \\
\hline & Notion & 1.67 & 1.15 & 47 & 14.05 & 6 & 4 & 4 & 0.79 \\
\hline & Jury & 1.52 & 0.72 & 33 & 5.27 & 4 & 3 & 2 & 0.92 \\
\hline & Magazine & 1.81 & 1.21 & 65 & 16.15 & 8 & 1 & 0 & 0.88 \\
\hline & Mixture & 1.68 & 0.21 & 48 & 1.62 & 7 & 0 & 1 & 0.69 \\
\hline & Phase & 1.61 & 0.97 & 41 & 9.32 & 5 & 1 & 1 & 0.82 \\
\hline & Pollution & 1.52 & 0.11 & 33 & 1.28 & 9 & 0 & 0 & 0.76 \\
\hline & Posture & 1.34 & 0.98 & 22 & 9.46 & 7 & 1 & 1 & 0.86 \\
\hline & Routine & 1.62 & 1.11 & 42 & 12.77 & 7 & 1 & 1 & 1.00 \\
\hline & Session & 1.61 & 0.36 & 41 & 2.30 & 7 & 1 & 1 & 0.69 \\
\hline & Site & 1.93 & 0.65 & 86 & 4.46 & 4 & 10 & 10 & 0.90 \\
\hline & Sofa & 1.38 & 0.75 & 24 & 5.68 & 4 & 5 & 3 & 0.85 \\
\hline & Structure & 2.05 & 0.95 & 113 & 8.92 & 9 & 2 & 1 & 0.86 \\
\hline & Test & 2.17 & 0.75 & 149 & 5.61 & 4 & 3 & 12 & 1.00 \\
\hline \multirow[t]{9}{*}{ LEHF } & Assassin & 0.78 & 1.41 & 6 & 25.95 & 8 & 0 & 0 & 0.79 \\
\hline & Baron & 0.95 & 1.45 & 9 & 28.24 & 5 & 3 & 3 & 0.81 \\
\hline & Bouquet & 0.78 & 1.57 & 6 & 37.09 & 7 & 1 & 0 & 0.88 \\
\hline & Carton & 0.70 & 1.65 & 5 & 44.86 & 6 & 4 & 2 & 0.73 \\
\hline & Chagrin & 0.48 & 1.69 & 3 & 48.51 & 7 & 0 & 0 & 0.85 \\
\hline & Commerce & 1.11 & 1.49 & 13 & 30.94 & 8 & 2 & 1 & 0.80 \\
\hline & Empire & 1.20 & 1.82 & 16 & 66.42 & 6 & 5 & 2 & 0.72 \\
\hline & Grimace & 0.95 & 1.64 & 9 & 43.85 & 7 & 2 & 0 & 0.88 \\
\hline & Hangar & 0.48 & 1.28 & 3 & 18.85 & 6 & 0 & 1 & 0.74 \\
\hline
\end{tabular}


Appendix A (continued)

\begin{tabular}{|c|c|c|c|c|c|c|c|c|c|}
\hline Category & Stimulus & $\log E$ & Log FR & f-ENG & f-FR & Letters & NbFR & $\mathrm{NbE}$ & NLD \\
\hline & Harem & 0.30 & 1.20 & 2 & 15.95 & 5 & 1 & 1 & 0.78 \\
\hline & Liaison & 1.00 & 1.50 & 10 & 31.96 & 7 & 0 & 0 & 0.66 \\
\hline & Papa & 0.78 & 1.89 & 6 & 77.16 & 4 & 9 & 2 & 0.90 \\
\hline & Pardon & 0.90 & 1.65 & 8 & 44.93 & 6 & 3 & 1 & 0.80 \\
\hline & Photo & 1.23 & 1.98 & 17 & 94.59 & 5 & 1 & 0 & 0.85 \\
\hline & Plaque & 0.48 & 1.87 & 3 & 73.85 & 6 & 5 & 1 & 0.98 \\
\hline & Prudence & 0.48 & 1.30 & 3 & 20.07 & 8 & 1 & 0 & 0.80 \\
\hline & Revolver & 0.78 & 1.40 & 6 & 25.20 & 8 & 0 & 2 & 0.92 \\
\hline & Saint & 1.26 & 2.03 & 18 & 106.1 & 5 & 4 & 4 & 0.70 \\
\hline & Sentiment & 1.08 & 2.20 & 12 & 157.3 & 9 & 2 & 0 & 0.75 \\
\hline & Serpent & 0.70 & 1.32 & 5 & 21.08 & 7 & 4 & 0 & 0.66 \\
\hline & Solitude & 0.90 & 1.84 & 8 & 69.73 & 8 & 0 & 0 & 0.83 \\
\hline & Terrain & 0.95 & 1.87 & 9 & 74.73 & 7 & 2 & 0 & 0.86 \\
\hline & Torrent & 0.70 & 1.21 & 5 & 16.35 & 7 & 2 & 1 & 0.70 \\
\hline & Trait & 0.90 & 2.02 & 8 & 105.88 & 5 & 7 & 3 & 0.90 \\
\hline & Tribunal & 0.85 & 1.26 & 7 & 18.04 & 8 & 1 & 0 & 0.80 \\
\hline & Troupe & 0.30 & 2.02 & 2 & 105.41 & 6 & 5 & 0 & 1.00 \\
\hline & Usage & 0.60 & 1.68 & 4 & 47.97 & 5 & 1 & 0 & 0.71 \\
\hline & Villa & 1.08 & 1.53 & 12 & 33.72 & 5 & 4 & 1 & 0.80 \\
\hline & Vocation & 0.48 & 1.36 & 3 & 22.84 & 8 & 2 & 2 & 0.70 \\
\hline & Zinc & 0.60 & 1.24 & 4 & 17.30 & 4 & 0 & 1 & 0.83 \\
\hline \multirow[t]{30}{*}{ LELF } & Alphabet & 0.48 & 0.67 & 3 & 4.73 & 8 & 0 & 0 & 0.85 \\
\hline & Altitude & 0.70 & 0.84 & 5 & 6.96 & 8 & 2 & 2 & 0.86 \\
\hline & Banquet & 0.85 & 0.77 & 7 & 5.88 & 7 & 2 & 0 & 0.71 \\
\hline & Bikini & 0.30 & 0.32 & 2 & 2.09 & 6 & 0 & 0 & 0.93 \\
\hline & Bracelet & 0.85 & 0.98 & 7 & 9.53 & 8 & 0 & 0 & 0.81 \\
\hline & Cassette & 0.60 & 0.81 & 4 & 6.42 & 8 & 2 & 0 & 0.94 \\
\hline & Coma & 0.30 & 0.69 & 2 & 4.93 & 4 & 8 & 4 & 0.85 \\
\hline & Corset & 0.60 & 0.46 & 4 & 2.91 & 6 & 3 & 0 & 0.72 \\
\hline & Cube & 0.95 & 1.09 & 9 & 12.30 & 4 & 5 & 4 & 0.83 \\
\hline & Dragon & 1.00 & 1.09 & 10 & 12.23 & 6 & 0 & 0 & 0.84 \\
\hline & Duel & 0.70 & 0.77 & 5 & 5.95 & 4 & 4 & 5 & 0.85 \\
\hline & Fable & 0.48 & 0.99 & 3 & 9.80 & 5 & 4 & 4 & 0.84 \\
\hline & Famine & 0.90 & 0.83 & 8 & 6.76 & 6 & 3 & 0 & 0.92 \\
\hline & Fiasco & 0.30 & 0.33 & 2 & 2.16 & 6 & 0 & 0 & 0.75 \\
\hline & Folklore & 0.48 & 0.58 & 3 & 3.78 & 8 & 0 & 0 & 0.85 \\
\hline & Fusion & 0.78 & 0.77 & 6 & 5.95 & 6 & 0 & 0 & 0.61 \\
\hline & Graffiti & 0.48 & 0.62 & 3 & 4.19 & 8 & 3 & 0 & 0.93 \\
\hline & Intrusion & 0.70 & 0.58 & 5 & 3.78 & 9 & 0 & 0 & 0.69 \\
\hline & Jargon & 0.85 & 0.64 & 7 & 4.32 & 6 & 0 & 0 & 0.69 \\
\hline & Martyr & 0.90 & 0.95 & 8 & 8.92 & 6 & 0 & 0 & 0.81 \\
\hline & Mule & 0.95 & 0.95 & 9 & 8.99 & 4 & 12 & 8 & 0.83 \\
\hline & Olive & 1.20 & 0.99 & 16 & 9.86 & 5 & 1 & 1 & 0.83 \\
\hline & Panorama & 0.48 & 0.71 & 3 & 5.14 & 8 & 0 & 0 & 0.89 \\
\hline & Patio & 0.30 & 0.81 & 2 & 6.42 & 5 & 2 & 1 & 0.70 \\
\hline & Prose & 0.85 & 0.52 & 7 & 3.31 & 5 & 6 & 4 & 0.93 \\
\hline & Rotation & 0.95 & 0.55 & 9 & 3.58 & 8 & 3 & 1 & 0.70 \\
\hline & Sermon & 0.95 & 0.81 & 9 & 6.42 & 6 & 0 & 0 & 0.71 \\
\hline & Tact & 0.70 & 0.68 & 5 & 4.80 & 4 & 4 & 5 & 0.94 \\
\hline & Yacht & 0.78 & 0.68 & 6 & 4.80 & 5 & 0 & 0 & 0.93 \\
\hline & Zoo & 1.00 & 0.81 & 10 & 6.49 & 3 & 2 & 7 & 0.77 \\
\hline \multirow[t]{16}{*}{ HE-controls } & Bathroom & 1.60 & & 40 & & 8 & & 0 & \\
\hline & Beard & 1.41 & & 26 & & 5 & & 3 & \\
\hline & Bedroom & 1.83 & & 68 & & 7 & & 0 & \\
\hline & Birthday & 1.34 & & 22 & & 8 & & 0 & \\
\hline & Blanket & 1.52 & & 33 & & 7 & & 0 & \\
\hline & Breast & 1.90 & & 80 & & 6 & & 0 & \\
\hline & Bullet & 1.40 & & 25 & & 6 & & 4 & \\
\hline & Cattle & 1.53 & & 34 & & 6 & & 3 & \\
\hline & Chest & 1.71 & & 51 & & 5 & & 3 & \\
\hline & Chicken & 1.63 & & 43 & & 7 & & 1 & \\
\hline & Clock & 1.62 & & 42 & & 5 & & 7 & \\
\hline & Cloth & 1.72 & & 52 & & 5 & & 2 & \\
\hline & Clothing & 1.65 & & 45 & & 8 & & 1 & \\
\hline & Darkness & 1.76 & & 57 & & 8 & & 0 & \\
\hline & Disease & 1.95 & & 90 & & 7 & & 0 & \\
\hline & Dust & 1.73 & & 54 & & 4 & & 11 & \\
\hline
\end{tabular}

(continued on next page) 
Appendix A (continued)

\begin{tabular}{|c|c|c|c|c|c|c|c|c|c|}
\hline Category & Stimulus & $\log E$ & Log FR & f-ENG & f-FR & Letters & NbFR & $\mathrm{NbE}$ & NLD \\
\hline & Elbow & 1.46 & & 29 & & 5 & & 0 & \\
\hline & Emphasis & 1.62 & & 42 & & 8 & & 1 & \\
\hline & Entrance & 1.75 & & 56 & & 8 & & 0 & \\
\hline & Factory & 1.77 & & 59 & & 7 & & 1 & \\
\hline & Fellow & 1.86 & & 72 & & 6 & & 5 & \\
\hline & Freedom & 2.03 & & 106 & & 7 & & 0 & \\
\hline & Guilt & 1.59 & & 39 & & 5 & & 4 & \\
\hline & Heaven & 1.66 & & 46 & & 6 & & 2 & \\
\hline & Height & 1.68 & & 48 & & 6 & & 1 & \\
\hline & Holiday & 1.91 & & 82 & & 7 & & 0 & \\
\hline & Illness & 1.61 & & 41 & & 7 & & 0 & \\
\hline & Inquiry & 1.76 & & 57 & & 7 & & 1 & \\
\hline & Knife & 1.69 & & 49 & & 5 & & 0 & \\
\hline & Laughter & 1.57 & & 37 & & 8 & & 1 & \\
\hline & Lawn & 1.46 & & 29 & & 4 & & 7 & \\
\hline & Leather & 1.58 & & 38 & & 7 & & 3 & \\
\hline & Luck & 1.66 & & 46 & & 4 & & 12 & \\
\hline & Mistake & 1.88 & & 76 & & 7 & & 0 & \\
\hline & Mood & 1.73 & & 54 & & 4 & & 8 & \\
\hline & Network & 1.51 & & 32 & & 7 & & 0 & \\
\hline & Owner & 1.81 & & 64 & & 5 & & 1 & \\
\hline & Pride & 1.61 & & 41 & & 5 & & 5 & \\
\hline & Queen & 1.72 & & 53 & & 5 & & 1 & \\
\hline & Schedule & 1.46 & & 29 & & 8 & & 0 & \\
\hline & Sheet & 1.76 & & 57 & & 5 & & 5 & \\
\hline & Shell & 1.72 & & 52 & & 5 & & 5 & \\
\hline & Skill & 1.91 & & 81 & & 5 & & 4 & \\
\hline & Skirt & 1.54 & & 35 & & 5 & & 1 & \\
\hline & Slope & 1.53 & & 34 & & 5 & & 3 & \\
\hline & Steel & 1.66 & & 46 & & 5 & & 4 & \\
\hline & Straw & 1.41 & & 26 & & 5 & & 3 & \\
\hline & Stream & 1.79 & & 61 & & 6 & & 2 & \\
\hline & Strength & 2.00 & & 100 & & 8 & & 0 & \\
\hline & Target & 1.70 & & 50 & & 6 & & 0 & \\
\hline & Throat & 1.71 & & 51 & & 6 & & 1 & \\
\hline & Thumb & 1.49 & & 31 & & 5 & & 1 & \\
\hline & Tongue & 1.62 & & 42 & & 6 & & 0 & \\
\hline & Weather & 1.85 & & 71 & & 7 & & 3 & \\
\hline & Wedding & 1.58 & & 38 & & 7 & & 4 & \\
\hline & Welfare & 1.83 & & 68 & & 7 & & 0 & \\
\hline & Wheel & 1.73 & & 54 & & 5 & & 0 & \\
\hline & Wing & 1.80 & & 63 & & 4 & & 11 & \\
\hline & Wrist & 1.49 & & 31 & & 5 & & 4 & \\
\hline & Writer & 1.80 & & 63 & & 6 & & 3 & \\
\hline \multirow{25}{*}{ LE-controls } & Airplane & 0.78 & & 6 & & 8 & & 0 & \\
\hline & Backbone & 0.70 & & 5 & & 8 & & 0 & \\
\hline & Backup & 0.60 & & 4 & & 6 & & 0 & \\
\hline & Bakery & 0.70 & & 5 & & 6 & & 1 & \\
\hline & Beaver & 0.48 & & 3 & & 6 & & 4 & \\
\hline & Beetle & 0.95 & & 9 & & 6 & & 0 & \\
\hline & Betrayal & 0.90 & & 8 & & 8 & & 0 & \\
\hline & Boyhood & 0.70 & & 5 & & 7 & & 0 & \\
\hline & Buddy & 0.85 & & 7 & & 5 & & 2 & \\
\hline & Burglar & 0.70 & & 5 & & 7 & & 0 & \\
\hline & Cowboy & 0.78 & & 6 & & 6 & & 0 & \\
\hline & Cradle & 1.00 & & 10 & & 6 & & 0 & \\
\hline & Crow & 0.90 & & 8 & & 4 & & 6 & \\
\hline & Cutlery & 0.48 & & 3 & & 7 & & 0 & \\
\hline & Dagger & 0.48 & & 3 & & 6 & & 2 & \\
\hline & Dime & 0.70 & & 5 & & 4 & & 9 & \\
\hline & Drawback & 0.78 & & 6 & & 8 & & 0 & \\
\hline & Drought & 0.78 & & 6 & & 7 & & 3 & \\
\hline & Dryer & 0.48 & & 3 & & 5 & & 1 & \\
\hline & Flaw & 0.95 & & 9 & & 4 & & 9 & \\
\hline & Folder & 0.70 & & 5 & & 6 & & 6 & \\
\hline & Frog & 0.95 & & 9 & & 4 & & 3 & \\
\hline & Garlic & 0.85 & & 7 & & 6 & & 0 & \\
\hline & Gateway & 0.70 & & 5 & & 7 & & 0 & \\
\hline & Grid & 0.70 & & 5 & & 4 & & 5 & \\
\hline
\end{tabular}


Appendix A (continued)

\begin{tabular}{|c|c|c|c|c|c|c|c|c|c|}
\hline Category & Stimulus & $\log E$ & Log FR & f-ENG & f-FR & Letters & NbFR & $\mathrm{NbE}$ & NLD \\
\hline & Grocery & 0.78 & & 6 & & 7 & & 1 & \\
\hline & Gunman & 0.48 & & 3 & & 6 & & 1 & \\
\hline & Hardware & 0.70 & & 5 & & 8 & & 0 & \\
\hline & Hawk & 0.95 & & 9 & & 4 & & 4 & \\
\hline & Haze & 0.90 & & 8 & & 4 & & 10 & \\
\hline & Hive & 0.60 & & 4 & & 4 & & 10 & \\
\hline & Jigsaw & 0.48 & & 3 & & 6 & & 0 & \\
\hline & Kidney & 0.95 & & 9 & & 6 & & 0 & \\
\hline & Kite & 0.70 & & 5 & & 4 & & 6 & \\
\hline & Kitten & 0.90 & & 8 & & 6 & & 1 & \\
\hline & Lettuce & 0.85 & & 7 & & 7 & & 0 & \\
\hline & Locker & 0.85 & & 7 & & 6 & & 4 & \\
\hline & Lowland & 0.85 & & 7 & & 7 & & 0 & \\
\hline & Maple & 0.60 & & 4 & & 5 & & 0 & \\
\hline & Mischief & 0.60 & & 4 & & 8 & & 0 & \\
\hline & Moisture & 0.78 & & 6 & & 8 & & 0 & \\
\hline & Napkin & 0.85 & & 7 & & 6 & & 0 & \\
\hline & Onset & 0.60 & & 4 & & 5 & & 1 & \\
\hline & Peanut & 0.78 & & 6 & & 6 & & 0 & \\
\hline & Pebble & 0.95 & & 9 & & 6 & & 0 & \\
\hline & Scarcity & 0.70 & & 5 & & 8 & & 0 & \\
\hline & Seaweed & 0.78 & & 6 & & 7 & & 0 & \\
\hline & Shawl & 0.85 & & 7 & & 5 & & 1 & \\
\hline & Shotgun & 0.70 & & 5 & & 7 & & 0 & \\
\hline & Shrine & 0.78 & & 6 & & 6 & & 1 & \\
\hline & Silt & 0.60 & & 4 & & 4 & & 11 & \\
\hline & Squirrel & 0.85 & & 7 & & 8 & & 0 & \\
\hline & Staple & 0.78 & & 6 & & 6 & & 1 & \\
\hline & Stripe & 0.85 & & 7 & & 6 & & 5 & \\
\hline & Suburb & 0.85 & & 7 & & 6 & & 0 & \\
\hline & Trash & 0.60 & & 4 & & 5 & & 2 & \\
\hline & Turmoil & 0.70 & & 5 & & 7 & & 0 & \\
\hline & Uproar & 0.78 & & 6 & & 6 & & 0 & \\
\hline & Walnut & 0.70 & & 5 & & 6 & & 0 & \\
\hline & Willow & 0.85 & & 7 & & 6 & & 3 & \\
\hline
\end{tabular}

\section{References}

Alario, F.-X., Goslin, J., Michel, V., \& Laganaro, M. (2010). The functional origin of the foreign accent: Evidence from the syllable-frequency effect in bilingual speakers. Psychological Science, 21, 15-20.

American Clinical Neurophysiology Society (2006). Guideline 5: Guidelines for standard electrode position nomenclature. Journal of Clinical Neurophysiology, 23, 107-110.

Baayen, R. H. (2010). Demythologizing the word frequency effect: A discriminative learning perspective. The Mental Lexicon, 5, 436-461.

Baayen, R. H., Piepenbrock, R., \& Van Rijn, H. (1993). The CELEX lexical database [CD-ROM]. University of Pennsylvania Linguistic Data Consortium.

Balota, D. A., Yap, M. J., Cortese, M. J., Hutchison, K. A., Kessler, B., Loftis, B., et al. (2007). The English Lexicon Project. Behavior Research Methods, $39,445-459$.

Caramazza, A., \& Brones, I. (1979). Lexical access in bilinguals. Bulletin of the Psychonomic Society, 13, 212-214.

Cristoffanini, P., Kirsner, K., \& Milech, D. (1986). Bilingual lexical representation: The status of Spanish-English cognates. The Quarterly Journal of Experimental Psychology Section A, 38, 367-393.

Davis, C., Sánchez-Casas, R., García-Albea, J. E., Guasch, M., Molero, M., \& Ferré, P. (2010). Masked translation priming: Varying language experience and word type with Spanish-English bilinguals. Bilingualism: Language and Cognition, 13, 137-155.

De Groot, A. M. B., \& Nas, G. L. J. (1991). Lexical representation of cognates and noncognates in compound bilinguals. Journal of Memory and Language, 30, 90-123.

Delorme, A., \& Makeig, S. (2004). EEGLAB: An open source toolbox for analysis of single-trial EEG dynamics including independent component analysis. Journal of Neuroscience Methods, 134, 9-21.
Dijkstra, T. (2005). Bilingual visual word recognition and lexical access. In J. F. Kroll \& A. M. B. De Groot (Eds.), Handbook of bilingualism: Psycholinguistic approaches (pp. 178-201). Oxford University Press.

Dijkstra, T., Miwa, K., Brummelhuis, B., Sappelli, M., \& Baayen, H. (2010). How cross-language similarity and task demands affect cognate recognition. Journal of Memory and Language, 62, 284-301.

Dijkstra, T., \& Van Heuven, W. J. B. (2002). The architecture of the bilingual word recognition system: From identification to decision. Bilingualism: Language and Cognition, 5, 175-197.

Dijkstra, T., Grainger, J., \& Van Heuven, W. J. B. (1999). Recognition of cognates and interlingual homographs: The neglected role of phonology. Journal of Memory and Language, 41, 496-518.

Dijkstra, T., Van Jaarsveld, H., \& Ten Brinke, S. (1998). Interlingual homograph recognition: Effects of task demands and language intermixing. Bilingualism: Language and Cognition, 1, 51-66.

Duyck, W., Van Assche, E., Drieghe, D., \& Hartsuiker, R. J. (2007). Visual word recognition by bilinguals in a sentence context: Evidence for nonselective lexical access. Journal of Experimental Psychology: Learning, Memory, and Cognition, 33, 663-679.

Duyck, W., Vanderelst, D., Desmet, T., \& Hartsuiker, R. J. (2008). The frequency effect in second-language visual word recognition. Psychonomic Bulletin E' Review, 15, 850-855.

Font, N. (2001). Rôle de la langue dans l'accès au lexique chez les bilingues: Influence de la proximité orthographique et sémantique interlangue sur la reconnaissance visuelle des mots. Unpublished doctoral dissertation, Université Paul Valéry, Montpellier, France.

Geisser, S., \& Greenhouse, S. (1959). On methods in the analysis of profile data. Psychometrika, 24, 95-112.

Gollan, T. H., Montoya, R. I., Cera, C., \& Sandoval, T. C. (2008). More use almost always means a smaller frequency effect: Aging, bilingualism, and the weaker links hypothesis. Journal of Memory and Language, 58, 787-814. 
Gollan, T. H., \& Silverberg, N. B. (2001). Tip-of-the-tongue states in Hebrew-English bilinguals. Bilingualism: Language and Cognition, 4, 63-83.

Holcomb, P. J., \& Grainger, J. (2006). On the time-course of visual word recognition: An event-related potential investigation using masked repetition priming. Journal of Cognitive Neuroscience, 18, 1631-1643.

Kerkhofs, R., Dijkstra, T., Chwilla, D. J., \& De Bruin, E. R. A. (2006). Testing a model for bilingual semantic priming with interlingual homographs: RT and N400 effects. Brain Research, 1068, 170-183.

Keuleers, E., \& Brysbaert, M. (2010). Wuggy: A multilingual pseudoword generator. Behavior Research Methods, 42, 627-633.

Kirsner, K., Lalor, E., \& Hird, K. (1993). The bilingual lexicon: Exercise, meaning and morphology. In R. Schreuder \& B. Weltens (Eds.), The bilingual lexicon (pp. 215-248). Amsterdam: John Benjamins.

Kutas, M., \& Federmeier, K. D. (2011). Thirty years and counting: Finding meaning in the $\mathrm{N} 400$ component of the event-related brain potential (ERP). Annual Review of Psychology, 62, 621-647.

Lalor, E., \& Kirsner, K. (2000). Cross-lingual transfer effects between English and Italian cognates and noncognates. International Journal of Bilingualism, 4, 385-398.

Lau, E. F., Phillips, C., \& Poeppel, D. (2008). A cortical network for semantics: (de)constructing the N400. Nature Reviews Neuroscience, 9, 920-933.

Lemhöfer, K., \& Dijkstra, T. (2004). Recognizing cognates and interlingual homographs: Effects of code similarity in language-specific and generalized lexical decision. Memory E Cognition, 32, 533-550.

Lemhöfer, K., Dijkstra, T., \& Michel, M. (2004). Three languages, one ECHO: Cognate effects in trilingual word recognition. Language and Cognitive Processes, 19, 585-611.

Libben, M. R., \& Titone, D. A. (2009). Bilingual lexical access in context: Evidence from eye movements during reading. Journal of Experimental Psychology: Learning, Memory, and Cognition, 35, 381-390.

McDonald, S. A., \& Shillcock, R. C. (2001). Rethinking the word frequency effect: the neglected role of distributional information in lexical processing. Language and Speech, 44, 295-323.

Midgley, K. J., Holcomb, P. J., \& Grainger, J. (2011). Effects of cognate status on word comprehension in second language learners: An ERP investigation. Journal of Cognitive Neuroscience, 23, 1634-1647.

Midgley, K. J., Holcomb, P. J., Van Heuven, W. J. B., \& Grainger, J. (2008). An electrophysiological investigation of cross-language effects of orthographic neighborhood. Brain Research, 1246, 123-135.

Münte, T. F., Wieringa, B. M., Weyerts, H., Szentkuti, A., Matzke, M., \& Johannes, S. (2001). Differences in brain potentials to open and closed class words: Class and frequency effects. Neuropsychologia, 39, 91-102.

New, B., Pallier, C., Ferrand, L., \& Matos, R. (2001). Une base de données lexicales du français contemporain sur Internet: Lexique. L'Année Psychologique, 101, 447-462.

Oldfield, R. C. (1971). The assessment and analysis of handedness: The Edinburgh inventory. Neuropsychologia, 9, 97-113.
Sánchez-Casas, R. M., Davis, C. W., \& García-Albea, J. E. (1992). Bilingual lexical processing: Exploring the cognate/non-cognate distinction. European Journal of Cognitive Psychology, 4, 293-310.

Sánchez-Casas, R., \& García-Albea, J. E. (2005). The representation of cognate and noncognate words in bilingual memory. Can cognate status be characterized as a special kind of morphological relation? In J. F. Kroll \& A. M. B. De Groot(Eds.), Handbook of bilingualism: Psycholinguistic approaches (pp. 226-250). Oxford: Oxford University Press.

Scarborough, D. L., Gerard, L., \& Cortese, C. (1984). Independence of lexical access in bilingual word recognition. Journal of Verbal Learning and Verbal Behavior, 23, 84-99.

Schepens, J., Dijkstra, T., \& Grootjen, F. (2012). Distributions of cognates in Europe as based on Levenshtein distance. Bilingualism: Language and Cognition, 15, 157-166.

Schepens, J., Dijkstra, T., Grootjen, F., \& Van Heuven, W. J. B. (submitted for publication). Cross-language distributions of high frequency and phonetically similar cognates.

Schutter, D. J. L. G., Leitner, C., Kenemans, J. L., \& Van Honk, J. (2006). Electrophysiological correlates of cortico-subcortical interaction: A cross-frequency spectral EEG analysis. Clinical Neurophysiology, 117, 381-387.

Schwartz, A. I., \& Kroll, J. F. (2006). Bilingual lexical activation in sentence context. Journal of Memory and Language, 55, 197-212.

Schwartz, A. I., Kroll, J. F., \& Diaz, M. (2007). Reading words in Spanish and English: Mapping orthography to phonology in two languages. Language and Cognitive Processes, 22, 106-129.

Soares, C., \& Grosjean, F. (1984). Bilinguals in a monolingual and a bilingual speech mode: The effect on lexical access. Memory $\mathcal{E}^{\prime}$ Cognition, 12, 380-386.

Strijkers, K., Costa, A., \& Thierry, G. (2010). Tracking lexical access in speech production: Electrophysiological correlates of word frequency and cognate effects. Cerebral Cortex, 20, 912-928.

Van Assche, E., Drieghe, D., Duyck, W., Welvaert, M., \& Hartsuiker, R. J. (2010). The influence of semantic constraints on bilingual word recognition during sentence reading. Journal of Memory and Language, 64, 88-107.

Van Assche, E., Duyck, W., Hartsuiker, R. J., \& Diependaele, K. (2009). Does bilingualism change native-language reading? Cognate effects in a sentence context. Psychological Science, 20, 923-927.

Van Hell, J. G., \& De Groot, A. M. B. (2008). Sentence context modulates visual word recognition and translation in bilinguals. Acta Psychologica, 128, 431-451.

Van Hell, J. G., \& Dijkstra, T. (2002). Foreign language knowledge can influence native language performance in exclusively native contexts. Psychonomic Bulletin \& Review, 9, 780-789.

Van Petten, C., \& Kutas, M. (1990). Interactions between sentence context and word frequency in event-related brain potentials. Memory $\mathcal{E}$ Cognition, 18, 380-393.

Voga, M., \& Grainger, J. (2007). Cognate status and cross-script translation priming. Memory E' Cognition, 35, 938-952. 